\title{
Development of Advanced Polymeric Reflector for CSP Applications
}

\author{
Final Report \\ March 28, 2013
}

Lead Organization:

Other Team Members:
Abengoa Solar Inc (ASI)

Deposition Technology Innovations Inc (DTI) Science Applications International Corp. (SAIC) Swisher and Associates 


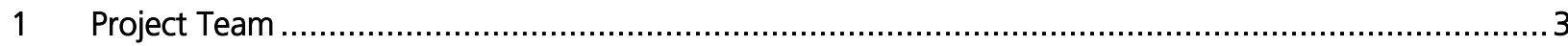

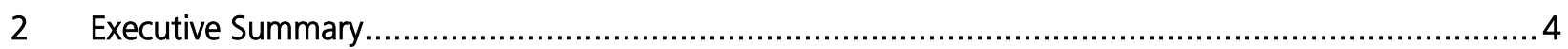

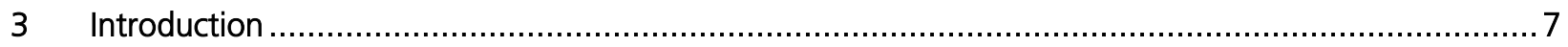

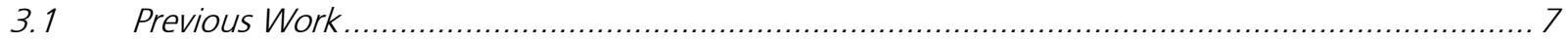

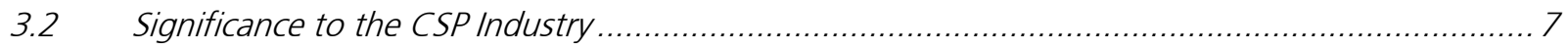

3.3 Quality Criteria for Reflective Film .............................................................................. 8

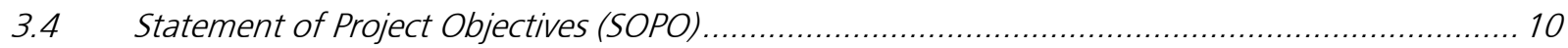

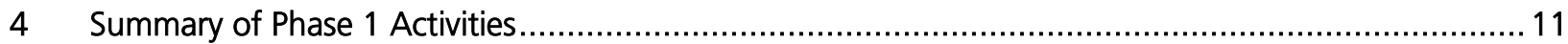

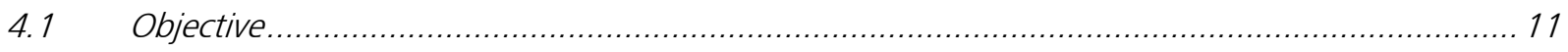

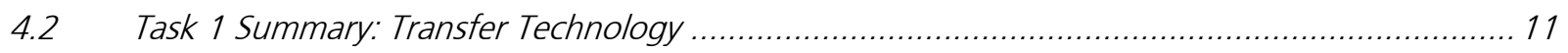

4.3 Task 2 Summary: Replicate Previous Quality ..................................................................... 11

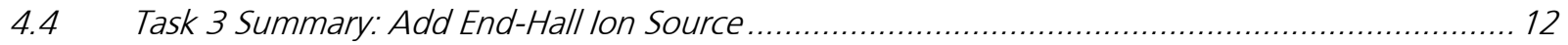

4.5 Task 4 Summary: Modify Process Cost Model.................................................................. 13

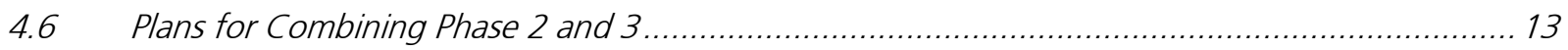

4.7 Summary and Conclusions from Phase 1 Work .............................................................. 14

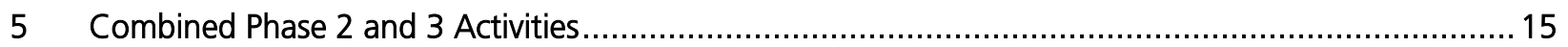

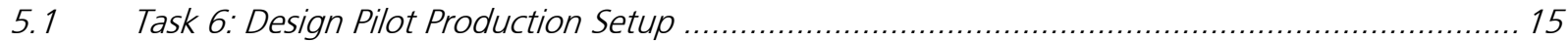

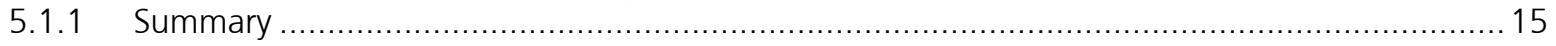

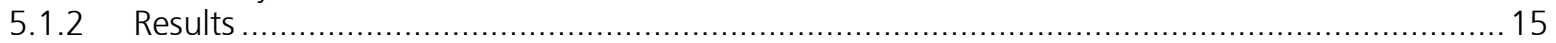

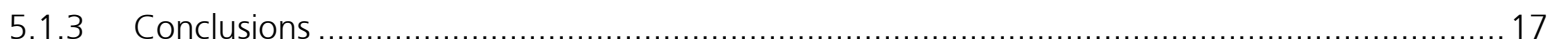

5.2 Task 7: Demonstrate Automatic Rate Control and Long Runs.............................................. 17

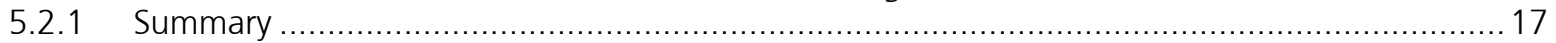

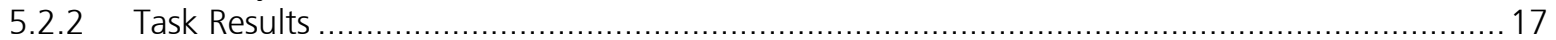

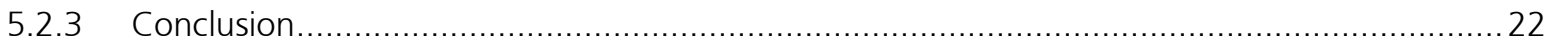

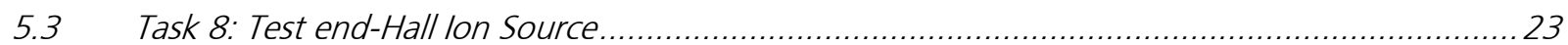

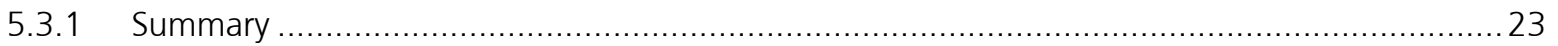

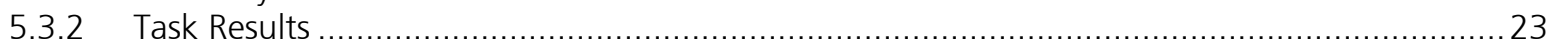

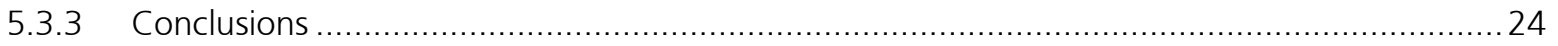

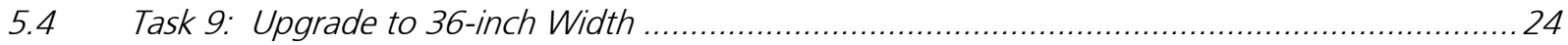

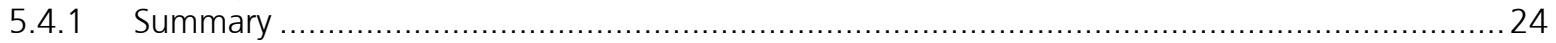

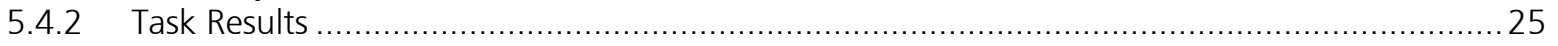

5.5 Task 10: Produce and Test 36-inch Wide Samples ................................................................26

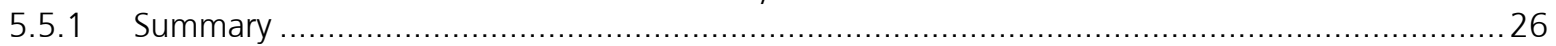

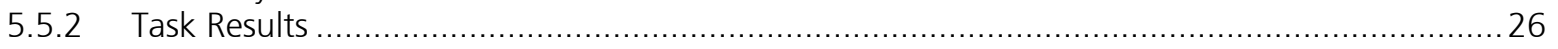

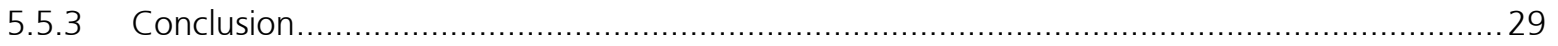

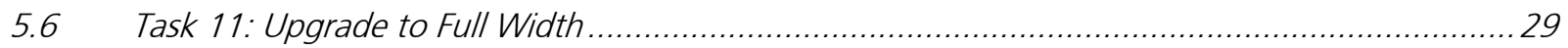

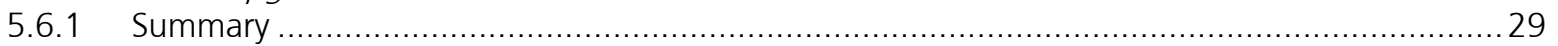

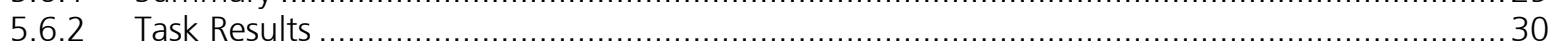

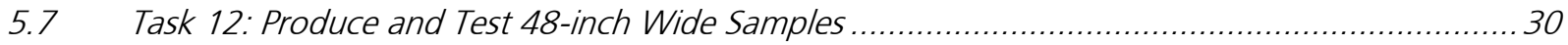

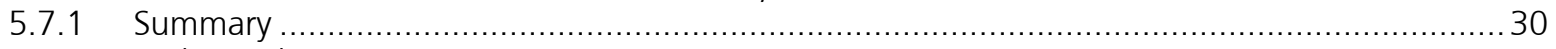

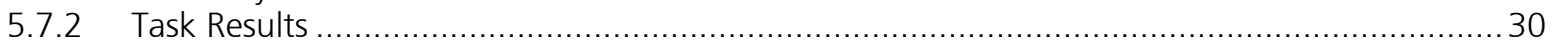


Development of Advanced Polymeric Reflector for CSP Applications

DE-FC36-08GO18036

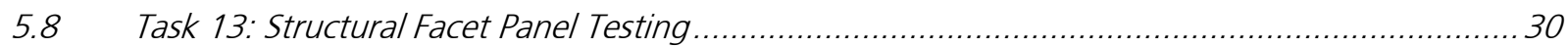

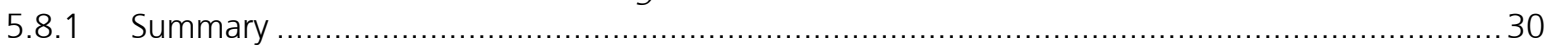

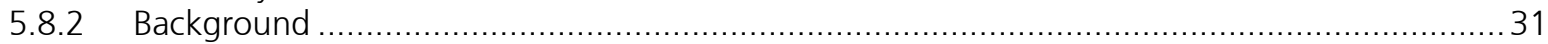

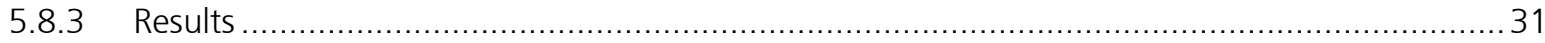

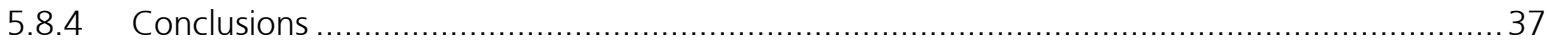

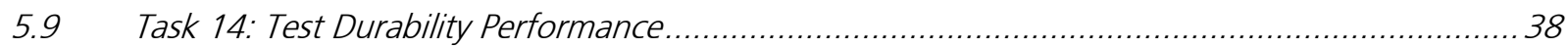

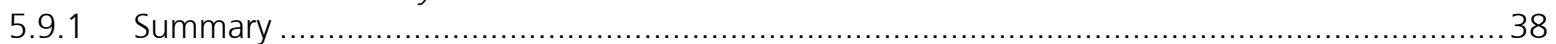

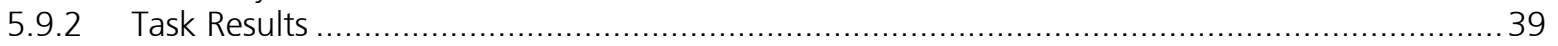

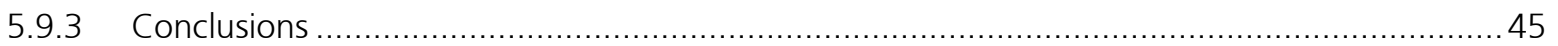

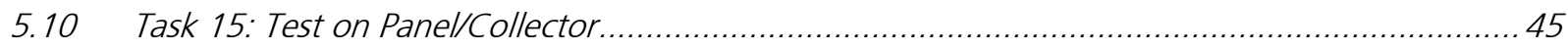

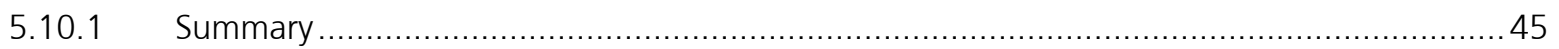

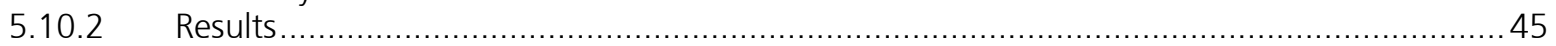

5.10.3 Conclusions .................................................................... Error! Bookmark not defined.

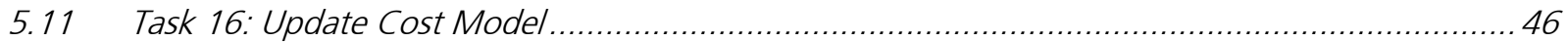

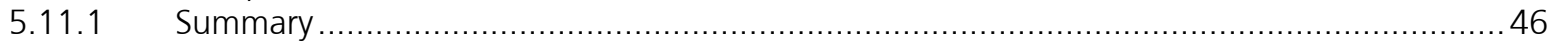

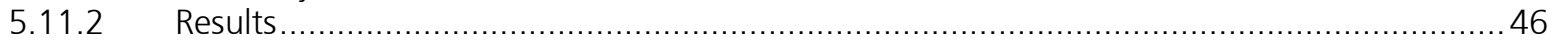

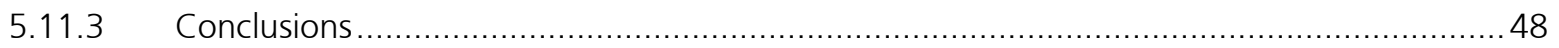

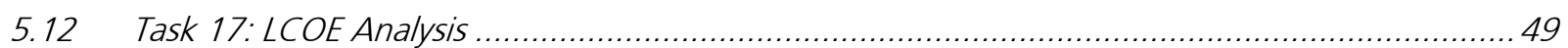

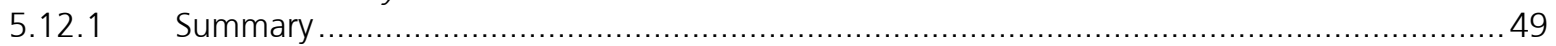

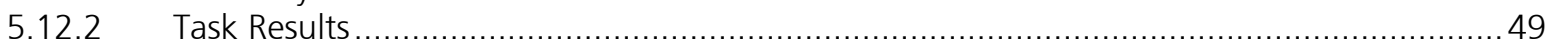

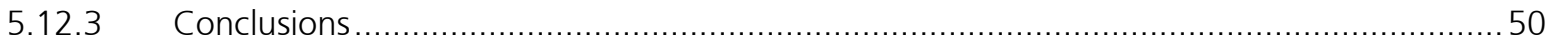

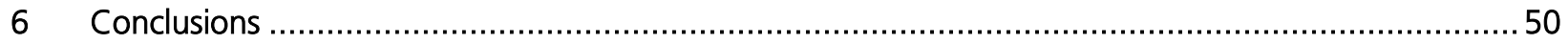

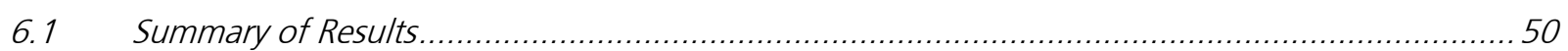

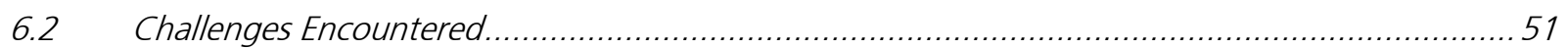

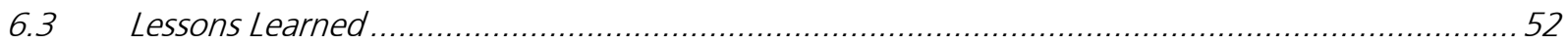

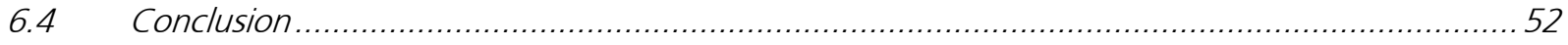




\section{Project Team}

Abengoa Solar

SAIC

DTI

Swisher \& Associates
Keith Boyle, Project Manager

Richard Treglio, Lead Process Engineer

Hildie Henderson, Project Coordination

Dr. Russell Smilgys, Scientist

Jerry Noblin, Head Engineer

Dan Rippere, Electron beam Technician

Richard Swisher, Principal 


\section{Executive Summary}

The joint Abengoa Solar/DOE project "Development of Advanced Polymeric Reflector for CSP Applications" was initiated to scale-up and further develop a previously demonstrated advanced solar reflecting material (ASRM) for use in CSP applications. This ASRM could be a promising thin film reflector technology because it enables innovative new design approaches to low-cost solar concentrators.

\section{Goals and Objectives}

The ASRM must address the following quality criteria for commercial relevance:

- High Solar Weighted Reflectance (95\%-97\%),

- Scrub-Abrasion Resistance (allow contact cleaning),

- Long Performance Life (30 years outdoor CSP deployment)

- Competitive Price

The primary objectives of the project were pursued in two phases, where phase two was a combination of phase two and three from the original award's three phase scope.

1. ASRM process transferred from lab to commercial roll to roll environment while retaining quality, and updating a cost model then estimating ASRM production costs.

2. ASRM scaled up to full width (4 feet) to demonstrate limited production, and creation of a reflector to use produced ASRM in an outdoor field validation. The ASRM cost model is fed into Abengoa Solar's system model to evaluate overall commercial viability.

\section{$\underline{\text { Results }}$}

For the first phase, the production process was successfully transitioned from the laboratory scale to limited 12 -inch width on a commercial roll coater. Highly reflective ( 96.5\% solar weighted reflectance) material was produced, with a durable top-coat that survived both accelerated weathering tests and scrub testing simulating 30 years of wear in the solar field. Updated cost models indicate a selling price within project targets. This price was very competitive with other reflective films on the market and met DOE cost goals. Based on these positive results, the decision was made to extend the project to a combined Phase 2 and 3.

For the second phase (combined phase 2 and 3 from original award scope), the project moved from a 12-inch wide to a 30-inch wide deposition area and was able to obtain prototype films with a high quality coating or a high deposition rate coating, but not both criteria concurrently at full width. The production process could not concurrently achieve required quality, durability, and cost when the deposition width was increased the final step to 30 inches. 
At the end of the second phase, the most economic ASRM prototypes showed:

- Reflectivity: above $95 \%$ solar weighted value

- Scrub Resistance: mixed, good macroscopic but expanded pinholes

- Long Life: inconsistent test results, not product ready

- Competitive Price: cost higher than current market

The reflective film combined with an innovative composite panel reflector design are estimated to reduce LCOE by about $4.4 \%$; however, the issues present in the wide width prototypes make this process risky and finding an alternate approach a likely better path.

\section{Summary of Lessons Learned}

Throughout this project several lessons were learned which will help with further projects. At high temperatures severe warping and PET breakdown is observed. The limitation in temperature restricts the deposition rate possible, which has a direct negative effect on film financial viability.

Overheating the PET web was a constant challenge, caused mainly by the ion beam assist used in the process. Without the ion source assistance, severe crazing was present in the mirror film. As deposition width and rate is increased, balancing crazing and warping became more difficult. In the future, an alternate method to achieve cost effective film density is needed.

During the deposition process of Alumina, the ejection of Alumina pieces can damage the film and jam or fail the deposition equipment. Severe spitting was observed during the Alumina deposition as rates increased. Several approaches were taken to minimize the spitting, but the spitting was still present at high deposition rates.

Cost modeling the film production process shows the largest cost contribution comes from the high capital requirement for a production vacuum chamber. This means that cost reduction measures must focus on getting more film from a machine: reduce the alumina layer thickness, make a wider film, or increase the alumina deposition rate.

The LCOE savings estimate breakdown for using the ASRM on a composite panel instead of glass mirrors shows energy production increases account for $44 \%$ of the overall benefit and solar field component cost reductions account for the remaining $56 \%$ of benefit. 


\section{Research implications}

This project attempted to deposit extremely thick and dense protective barrier onto a film stack with a PET substrate. The target thickness was very high for thin film products; particularly since large areas and long production lengths of film are needed to make the final product economic. The technical investigations in this project centered on maintaining a quality barrier (i.e. dense film) while evaporating alumina with a high deposition rate onto a low cost PET substrate. The project found that the proposed configuration, particularly direct ion bombardment, provides too narrow a solution space to effectively and economically produce the ASRM attempted. 


\section{Introduction}

This report presents technical results achieved under the DOE project "Development of Advanced Polymeric Reflector for CSP Applications". This project sought to develop and scale-up a previously demonstrated ASRM for use in CSP applications. This technology is promising not only for its potential lower cost for reflector surfaces, but also because the design flexibility and durability associated with non-glass reflectors may allow entirely new approaches to low-cost concentrator design. Under this project, an ASRM produced by SAIC and NREL in 2003, has been transitioned from a laboratory-scale to limited production runs on a commercial scale roll coater.

\subsection{Previous Work}

SAIC and NREL developed an advanced solar reflective material that consists of a polymer or metal foil substrate coated with a copper layer, followed by a layer of silver, and finally by a protective optically transparent alumina top coating, Figure 1. Early on, this basic design was recognized as having good potential, but the difficulty was in finding a durable top coating. The alumina top coating is essential to sustain high reflectance in outdoor service. The coating is deposited by a technique called ion-beam-assisted physical vapor deposition (IBAD).

\begin{tabular}{|r|c|}
\hline Top Protective Layer $\left(0.5-4 \mu \mathrm{m} \mathrm{Al}_{2} \mathrm{O}_{3}\right)$ \\
\hline \multicolumn{2}{|c|}{ Reflective Layer $(1000 \mathrm{~A} \mathrm{Ag})$} \\
\hline \multicolumn{2}{|c|}{ Metal Back Layer $(700 \mathrm{~A} \mathrm{Cu})$} \\
\hline Substrate (PET) & (Leveling Layer) \\
\hline
\end{tabular}

Figure 1 Coating structure of solar reflective material developed at SAIC

NREL sponsorship ended in 2004 after SAIC completed a laboratory-scale machine at its site in McLean, Virginia, and produced ASRM samples on a chrome plated steel substrate. Many of those samples continue to do well in outdoor exposure tests by NREL.

\subsection{Significance to the CSP Industry}

A high reflectance, scrub-resistant ASRM, such as the one being developed in this project, is a potentially significant development for the CSP industry. Glass mirrors are currently the industry standard for utility-scale solar power operations. However, these glass mirrors impose certain limits, their weight and fragility inhibiting 
potential design leaps needed to make solar power more competitive with fossil fuels. No reflective film on the market fully meets the industry's needs. As a result, only a small number of companies are attempting to develop reflective film-based collector designs. A long-lasting, inexpensive, durable, and highly reflective ASRM has the potential to make large impacts across the industry.

There are many benefits to replacing glass mirrors with alternatives that do not display some of the limitations of current glass reflectors:

- Design Constraints: The design constraints of glass provide the most compelling need for a solar reflective film. Currently, solar collectors must support the heavy weight of glass, which adds material and expense to their overall structure. With an appropriate facet backing, a reflective film can provide significant reductions to the solar collector structure and allow for a variety of innovative designs.

- Shape Limitations and Optical Efficiency: In testing, engineered facet panel backing materials have been able to hold improved shape and optical precision. Unlike glass, they can also be produced with higher curvature and unusual shapes. This enables improved optical efficiency and innovative design solutions.

- Transport Difficulty: Glass is both heavy and breakable, which makes it difficult and expensive to transport. Some breakage during transport is common. Reflective film is far lighter, transported in large rolls and does not shatter.

- Breakability in the Field: Mirrors are broken in the field every year, due to strong weather events and other occurrences, and must be replaced. In reflective films much more limited areas are affected by any damage. For example a small hole as opposed to shattered sections from high speed debris.

- Size: Glass mirrors become extremely difficult to handle at large sizes. Because of this, typical solar mirrors are produced at less than $1.7 \mathrm{~m}$ wide. When attached to a light-weight facet, the ASRM could be easily manipulated even at extremely large sizes, perhaps $5 \mathrm{~m}$ long or more. This simplifies collector construction and means fewer pieces which must be optically aligned.

\subsection{Quality Criteria for Reflective Film}

Some key capabilities needed in a reflective film include:

1. Scrub-Abrasion Resistance: In order to maintain peak reflectance over time, a reflective surface must be cleaned. Scrubbing is currently the best way to thoroughly clean CSP 
reflectors in the field; however this presents a limitation for reflective materials that have a low resistance to scrub-abrasion. Resistance to scrub-abrasion is a key capability which the ASRM in this project has over the reflective films available on the market today and is critical for maintaining high reflectance values in the solar field.

2. High Reflectance: Reflectance values should exceed $94 \%$, the typical level displayed by solar industry glass mirrors. Even a few percentage points difference translates to large power output differences when multiplied across an entire solar power plant. This allows a smaller solar field to meet a given power output threshold, and a smaller solar field results in saving from fewer solar field components (e.g. foundations, modules, receivers, reflectors). The ASRM produced in this project targets extremely high reflectance values, between 95\%-97\%.

3. Long Performance Life: The film must maintain performance over the 30 year expected lifetime of a solar plant. It must prove durable, and both weather and UV-resistant among other factors. Any sort of periodic replacement of a film reflector will have grave economic consequences on a potential plant, and drives the pursuit of a 30 year product lifetime.

A reflective film that can meet all of these criteria at a competitive cost has the potential to replace glass as the industry standard for solar applications. This can fuel innovative design, transforming the CSP landscape and pushing down the cost of solar energy in the race to compete with fossil fuels. 


\subsection{Statement of Project Objectives (SOPO)}

The statement of project objectives for the project outlines the key tasks for scaling up the technology from lab scale to limited commercial production.

\section{Phase 1}

Completed June 2008 -July 2010

Task 1. Transfer Technology

Task 2. Replicate Previous Quality

Task 3. Add End Hall ion source

Task 4. Modify Process Cost Model

Task 5. Project Management

\section{Combined Phase 2 and 3}

August 2010 - June 2012

Task 6. Design Pilot Production Setup

Task 7. Demonstrate Automatic Rate Control and Long Runs

Task 8. Test End Hall lon Source

Task 9. Upgrade to 36-inch Width

Task 10. Produce and Test 36-inch Wide Samples

Task 11. Upgrade to Full Width

Task 12. Produce and Test 48-inch Wide Limited Production Samples

Task 13. Structural Facet Panel Testing

Task 14. Test durability performance

Task 15. Test on Panel/Collector

Task 16. Update Cost Model

Task 17. LCOE Analysis

Task 18. Project Management 


\section{Summary of Phase 1 Activities}

Phase one of the project plan is made up of tasks 1-5. These tasks have been reported on in the Phase 1 Continuation Report and are summarized below.

\subsection{Objective}

The focus of Phase 1 was technology transfer and proof of concept. The goal was to transition the ASRM from the laboratory-scale to a limited commercial scale 12inch wide roll coater. Scale-up and cost parameters were collected to address the technical feasibility and cost of the process. The cost model was then updated to project the cost of full-scale commercial production

The tasks for the Phase were as follows:

Task 1. Transfer Technology

Task 2. Replicate Previous Quality

Task 3. Add End Hall ion source

Task 4. Modify Process Cost Model

Task 5. Project Management

\subsection{Task 1 Summary: Transfer Technology}

Task 1 was to transition the SAIC coating technology from the laboratory to the commercial environment at CSI/Marian. This allowed a commercial roll coater to become familiar with the technology and evaluate the issues associated with scaleup to commercial production

The roll coating machine at Marian was designed to metallize a 12 inch wide polymer web by sputtering, and was not initially equipped to perform IBAD. SAIC and CSI worked together to perform the necessary installation. This required the addition of cryopanels, a high voltage power supply, high capacity drum chillers, a gas manifold, 8-inch sputtering cathodes for depositing silver and copper, and installation of the SAIC IBAD hardware, including the electron beam gun, gridded ion source, and the quartz crystal monitor needed to measure deposition rates. The machine was successfully made operational for ASRM production in July 2009.

\subsection{Task 2 Summary: Replicate Previous Quality}

Task 2 was to replicate the quality of the ASRM previously created at NREL in 2002. Initial runs showed yellow and brown discoloration, and wrinkling due to overheating. Subsequent runs produced highly reflective material, but with poor alumina to silver adhesion. The adhesion issue was solved by re-calibrating the deposition rate and tuning process parameters such as drum temperature and process gas load.

High quality samples were produced in September of 2009, Figure 2. 
Four samples were sent to NREL for evaluation: Abengoa 5-8. NREL reflectance results for the samples were exceptionally high, between $96 \%$ - 97\% solar weighted reflectance. High quality reflective glass mirrors, by comparison, display reflectance of approximately $94 \%$. Samples retained high reflectance values after undergoing 1.7 months of NREL outdoor, as well as accelerated weathering testing. Accelerated weathering testing was performed in the BlueM weathering machine, in which temperatures are cycled up and down from ambient up to $85^{\circ} \mathrm{C}$ and $85 \%$ relative humidity.

In addition to positive weather resistance results, data from NREL scrub abrasion resistance testing indicated that the film is likely to withstand field scrubbing.

Samples underwent testing designed to simulate 30 years of scrub-cleaning in a commercial CSP solar field. Only small spots of damage were observed along the edges of the brush path after the 30 year equivalent test.

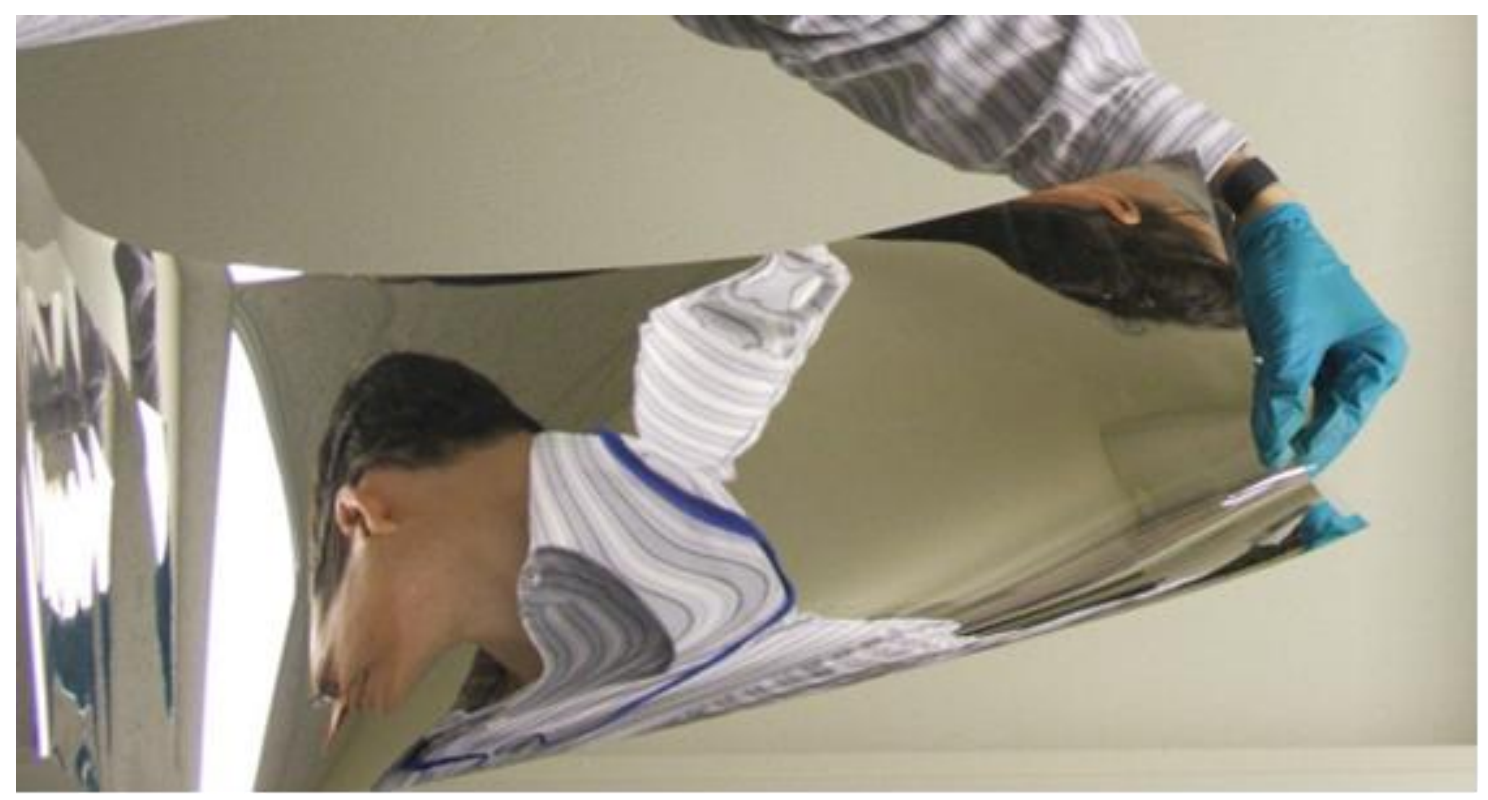

Figure 2 Image of the reflective film produced at Marion

\subsection{Task 3 Summary: Add End-Hall Ion Source}

Investigation of the end-Hall lon Source was moved to Phase 2. End-Hall ion sources are a preferred technology for commercialization, due to their relatively affordable cost and their low maintenance requirements. However investigation during Phase 1 indicated that typical end-Hall ion sources produce too low an ion beam energy for use in ASRM production. This led the team to suggest that the task be removed from the project scope. The Task was ultimately moved to Phase 2 , Task 8 after a promising new end-Hall Source design was discovered with potential for use in film production. 


\subsection{Task 4 Summary: Modify Process Cost Model}

Under Task 4, the ASRM cost model originally produced in 2003 by Swisher and Associates was updated. This included process information, machine cost, and material costs gathered during the Phase 1 work. The purpose was to evaluate and characterize process and cost issues that drive scale-up of the coating process to commercial production.

Cost model analysis indicated that process speed and the cost of alumina feed stock are the primary cost drivers. High process speed is necessary for a high annual production rate per machine. A high annual production drives down the amortized machine cost burden that is a part of the cost for each square meter of film. The need for process speed maximization caused the team to identify a two-drum machine with a two meter wide web as the target production setup. Increased web width and the number of drums increases net process through-put; however to stay within the constraints of practical and previously demonstrated commercial ventures the team selected the two-drum option with a two meter wide web.

High aluminum oxide feedstock costs were addressed by identifying plentiful sources of waste material alumina that could be recycled from other manufacturing operations.

A machine cost estimate was obtained from commercial machine manufacturers S.E. and Associates. A conservative thick alumina coating was assumed based on experience from the phase.

The resulting cost model revealed that the ASRM could be producible at competitive costs, comparable to, or slightly lower than other reflective films on the market.

\subsection{Plans for Combining Phase 2 and 3}

The phase 1 installation provided the team with an increased understanding of equipment and installation requirements for the pilot production setup. Based on this information, it became apparent that two distinct budget phases for the remaining scale-up were not only unnecessarily, but would introduce unnecessary cost and time inefficiencies into the project. Each step of the remaining scale-up was interrelated. Significant amounts of the Phase 3 scale-up would have to be completed during Phase 2 and lower costs/faster lead times could be realized by combining both. In addition, because both equipment installation costs and machine time are significant expenses, it would be important to avoid even small administrative delays between the phases. During delays, machine time would have to be purchased, or equipment de-installed to allow other customers into the machine. Based on this information, the decision was made by the DOE and the team that a combined Phase 2 and 3 represented the most logical and efficient path forward for the project. Step-wise Tasks and Go/No Go Decisions were established to provide appropriate staging and checks for the scale-up progress. 


\section{Location for Combined Phase 2 and 3}

Following completion of Phase 1, a pre-existing vacuum chamber was located with acceptable conditions for the Phase 2 work. The chamber had good pumping capabilities, capacity for a forty-eight inch wide web, and was available on a nearly exclusive basis for near-term project work. The chamber was located at the facilities of Deposition Technology Innovations (DTI) in Jeffersonville, Indiana, not far from the Marian facilities used for the Phase 1 work.

Simultaneously, Marian was able to re-quote their cost estimates for a machine for Phase 2 and 3, based on information collected during Phase 1. The new estimated cost of approximately was drastically higher than that offered at the outset of the project. This was unacceptable for project cost requirements. Additional vacuum chambers were investigated, and based on price and suitability, the DTI chamber was selected as the best candidate for the Phase 2 work.

\subsection{Summary and Conclusions from Phase 1 Work}

During Phase 1, the production process was successfully transitioned from the laboratory scale to limited 12 -inch width on a commercial roll coater. Highly reflective (96\%-97\% solar weighted reflectance) material was produced, with a durable topcoat that survived both accelerated weathering tests and scrub testing simulating 30 years of wear in the solar field. Based on these positive results, the decision was made to extend the project to a combined Phase 2 and 3. A suitable vacuum chamber for the Combined Phase 2 and 3 work was chosen, located at the facilities of Deposition Technology Innovations in Clarksville, Indiana. 


\section{Combined Phase 2 and 3 Activities}

Phase two 2 and three 3 of the original project plan were combined, and this combined phase is made up of tasks 6-17. These tasks are summarized below. The combined Phase 2 and 3 was a larger effort than Phase 1 and so there is added detail to reporting these results; each section has a summary, results and conclusions.

\subsection{Task 6: Design Pilot Production Setup}

\subsubsection{Summary}

The objective of Task 6 was to produce ready-to-build design drawings for the 48inch width pilot production setup. Detailed design drawings must specify equipment configuration, penetrations, atmosphere to vacuum connections (feedthroughs) into the vacuum chamber, locations of high voltage lines, cooling water connections, and process gas feed-ins. Process models were also developed to inform the design.

The full pilot scale system design was successfully completed. Appropriate equipment was chosen for the process scale-up, including large rotating trough electron beam guns which hold sufficient quantities of alumina for long deposition runs. An innovative end-Hall ion source was selected. Detailed design drawings were produced, incorporating experience from the first part of the phase. Magnetics testing was performed in order to determine the optimal orientation of the e-beam guns.

\subsubsection{Results}

\section{Equipment Selection}

The first step in the design process was to evaluate equipment appropriate to the scale-up. Large rotating trough electron beam guns, including associated controllers and power supplies from Telemark, were selected for their ability to hold large quantities of alumina sufficient for long 8-hour process runs. A Saintech brand high power end-Hall ion source was selected (described in detail in section 5.3). The unit showed promise based on high power output and low maintenance requirements. An optical monitor and multi-crystal quartz crystal monitors were selected for rate monitoring.

\section{Modeling}

Models were produced to predict deposition uniformity across the wide web. The data informed optimal equipment placement and spacing in the design. Uniformity considerations are important because deposition from a single source peaks directly above the gun, falling off near the edges, as seen in the single e-beam deposition profile below in Figure 3. By modeling different equipment spacing and source to drum distances, geometries were determined that would provide the most uniform 
profile across the web. E-beam powers were also input and it was determined that supplying extra power to the guns on the outside edges of the chamber provides a smoother profile, minimizing drop-off near the drum edges (see graphs below).

\section{Single E-beam Deposition Profile}

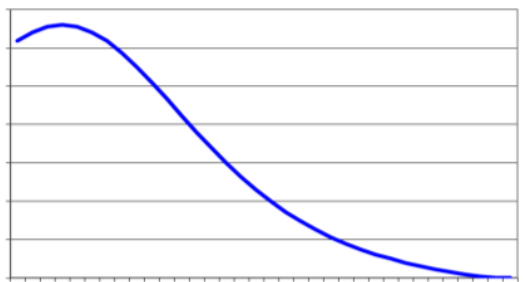

\section{Deposition Profile - Equal Power}

\section{Deposition Profile - Unequal Power}
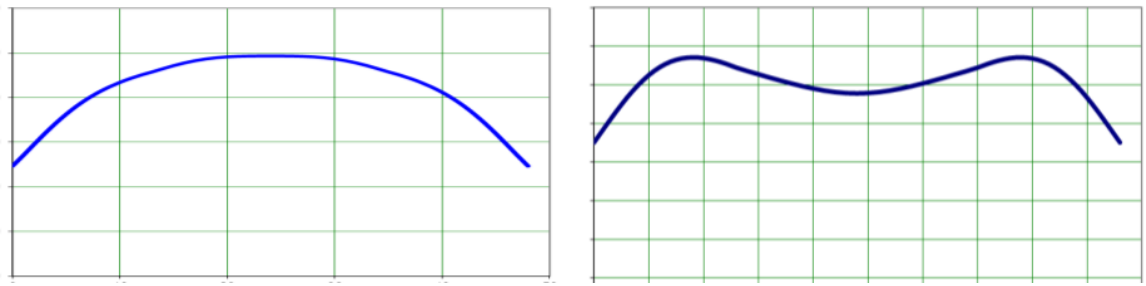

Figure 3 Modeled Electron Beam Deposition Profiles

\section{$\underline{\text { Design }}$}

An initial design was produced at the beginning of the phase, sufficient to install and test the single e-beam setup for the Task 7 work. It included general placement of the electron beam and ion source equipment for the full scale-up. The design was commissioned from System Control Technologies (SCT), a company which specializes in electron beam system design, and is shown in Figure 4.

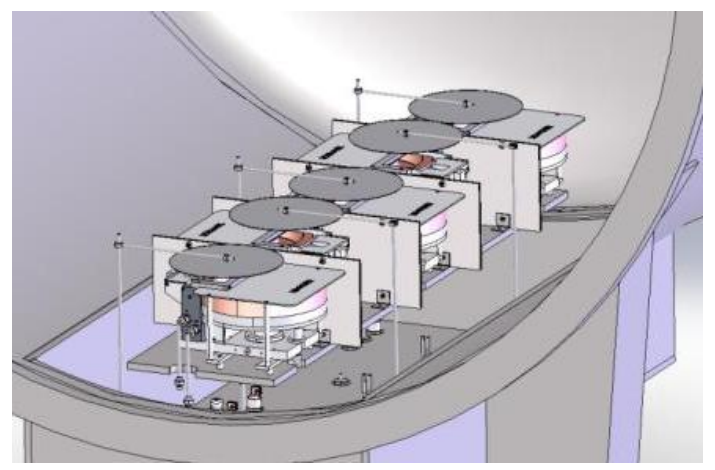

Figure 4. Initial System Design

Following Task 7, the design was refined and updated to reflect experience from the single e-beam source setup. Detailed equipment relationships and view angles were factored into the drawings. Design improvements were made, such as shortening and shielding of the high voltage leads to avoid undesirable arcing issues.

\section{Magnetics Testing}

As part of the revised scale-up design, magnetics testing was performed in order to determine an optimal e-beam orientation. Electron beam guns have strong permanent magnets designed in as part of the beam control mechanisms of the equipment. Deciding on an e-beam configuration is only possible by understanding 
the magnetic interplay between side by side guns. A "head to head" orientation in which all e-beams face the same direction was selected as a result of the testing. This work was performed as part of the Task 9 scale-up and is detailed in Section 5.4 .

\subsubsection{Conclusions}

The full pilot scale system design was successfully completed. Electron beam guns with a large rotating trough were estimated to hold sufficient quantities of alumina for long deposition runs. Initial evaluation indicated that an innovative end-Hall ion source would work. Finally, magnetics testing determined that a head-to-head orientation of the e-beam guns would produce the best deposition profile.

\subsection{Task 7: Demonstrate Automatic Rate Control and Long Runs}

\subsubsection{Summary}

The objective for Task 7 was to reproduce high quality 12 -inch wide film in the DTI chamber and to demonstrate that long IBAD deposition runs can be performed utilizing automatic rate control. Automatic control is necessary to ensure steady deposition rates and reduce operator involvement, as required in a commercial production environment. Long runs increase production rates and are needed to reduce the film production costs. Both conditions must be met to make production of the film cost-effective and commercially viable.

Multi-hour runs on automatic rate control were successfully achieved, using the quartz crystal monitor to measure the deposition rate. Using an on-site UV-VIS spectrometer, a 96\% reflectance was measured. The adhesion however was inconsistent. SEM images of the resulting film showed inconsistencies in the adhesion between the alumina and silver layers.

\subsubsection{Task Results}

A single source, 12 -inch wide IBAD setup was installed in the DTI vacuum chamber and tests were performed between July and November of 2012.

\section{Key Process Parameters}

Production of reflective film with the high quality exhibited in phase 1 requires calibration of a variety of different process parameters. High quality film is typically produced within a narrow range for each process parameter; however the correct range will vary based on chamber size, number of e-beam guns, and shifts in the other process parameters, creating a multivariate calibration problem. Understanding how variation of each parameter affects film quality and developing a standard set of process conditions is a key activity for the phase. The most important process parameters include:

- Deposition rate 
- $\quad$ Ion source current and voltage

- $\quad$ Drum temperature

- $\quad$ Process gas composition and dosage

- Chamber pressure

Ion source power is important due to its effects on film densification and bonding to the substrate. As shown in Figure 5 and detailed in the Michael Fulton's research
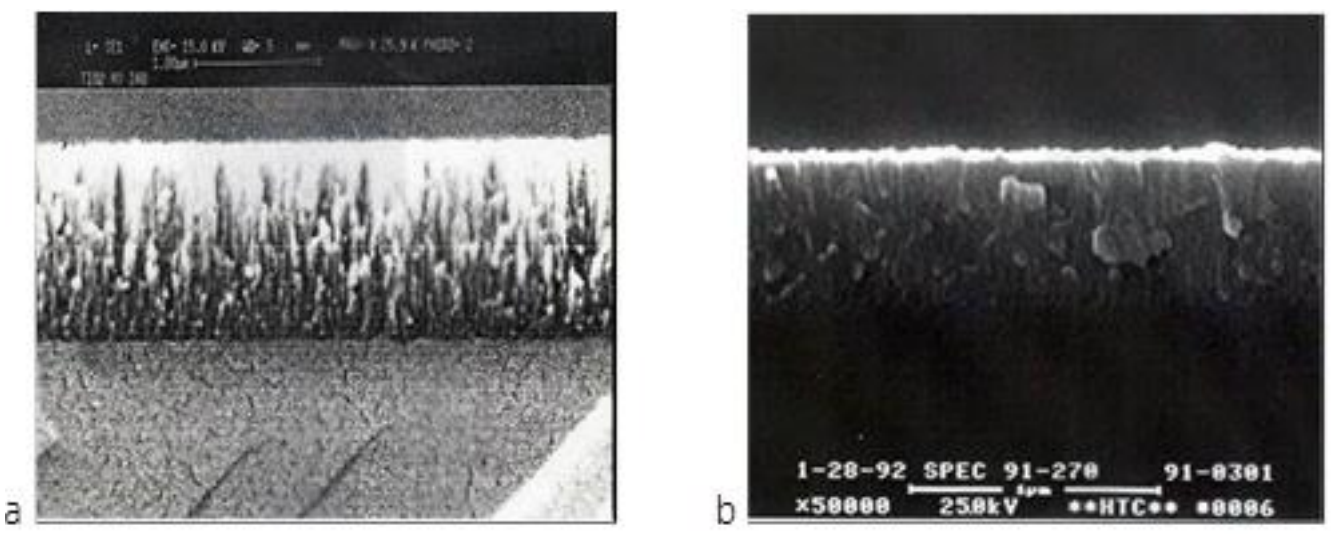

Figure 5 lon bombardment influence on $\mathrm{TiO}_{2}$ thin films with and without ion assist. The image (a) is without ion assist and (b) is with ion assist. Image taken with permission from Michael Fulton.

and other sources, the application of an ion beam pushes oxide layer growth into an amorphous phase. The beam energizes the substrate, altering the microstructure of the alumina as it is deposited. In the case of aluminum oxide, the ideal structure is a dense amorphous layer; however unassisted deposition typically forms cubic or hexagonal crystalline structures. The amorphous layer is superior because it is dense and continuous, whereas the crystalline structures form columnar growth, in which void spaces between each columnar region can allow penetration of moisture and other contaminants.

Correct calibration of ion energy is also important for proper adhesion to the substrate. Ion energy penetrates into the substrate allowing better bonding between deposited material and the substrate layer. However, the energies must be carefully balanced. Insufficient voltage means ions will not adequately penetrate the film and bonding will be inadequate. However, excess voltage increases internal compressive stresses in the deposition layer, causing film cracking and spalling. 
Drum temperature is another important factor in producing adherent, densely packed material. As seen in the drawing below, Figure 6, a high substrate tempera-

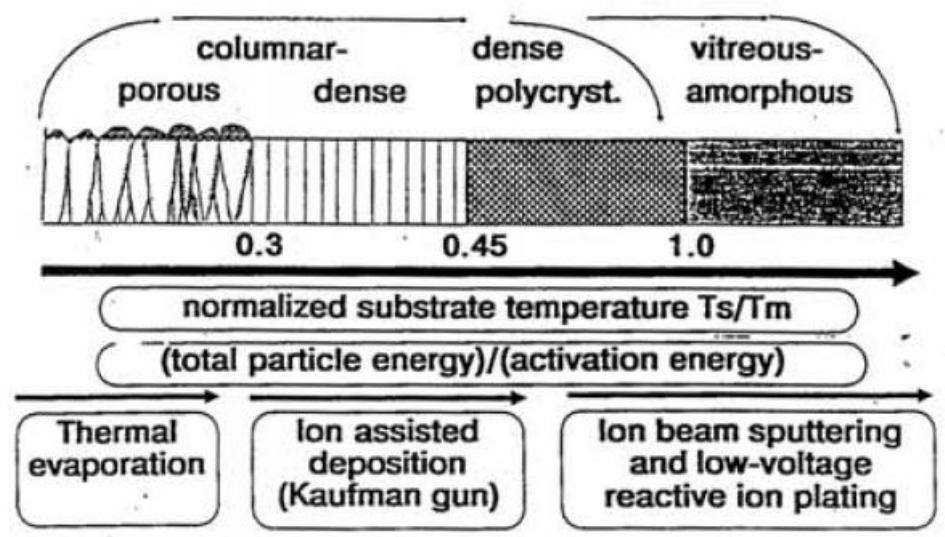

Figure 6 Diagram showing the relationship of crystalline structure from different forms of thin film growth courtesy of Michael Fulton. Ts is the substrate temperature and $\mathrm{Tm}$ is the melting point of the film material .

ture is needed to reach a dense amorphous thin film using thermal evaporation. By using ion assist or ion beam sputtering to increase the total particle energy, the substrate temperature can be reduced significantly while keeping film density. For the ASRM in question, high drum temperature is also unallowable. PET melting will occur if the drum is unable to provide sufficient cooling to balance the heat load of the molten alumina as it is deposited.

Process gas composition and dosing is another important factor. The correct proprietary process gas combinations provide a stoichiometric, highly transparent alumina layer, and may play a role in proper adhesion.

Chamber pressure is the final critical process parameter, affecting the results of all the above process parameters.

\section{Equipment Configuration}

Reaching a stable equipment configuration proved more challenging than expected due to a number of early equipment failures. Both the Telemark e-beam power supply and the Saintech end-Hall ion source failed during operation at high power.

The power supply initially used experienced multiple failures as soft start resistors overheated to glowing red at high power. The Saintech end-Hall ion source was unable to cool sufficiently under deposition conditions and experienced melt failure, as detailed in section 5.3. As a result, a CV-14 power supply (a venerable design) and gridded ion source from Phase 1 were reintegrated into the system. While not 
catastrophic, these equipment failures significantly delayed a stable equipment configuration, introducing large project delays and cost increases.

\section{Deposition Runs}

Process runs were completed between July and November 2011.

Automatic rate control was established using the quartz crystal sensors to monitor the deposition rate. Testing revealed that preconditioning of the alumina reduced spitting and ensured the most uniform deposition rate. Long multi-hour runs were successfully completed on automatic settings with minimal rate excursions.

Simultaneously, the process conditions were systematically calibrated with the goal of producing a high clarity, highly adhered deposition layer.

Initial film samples showed brown and yellow discoloration, as was expected for uncalibrated runs in the new chamber. Clarity increased incrementally with adjustments to the process parameters. During long process runs in September highly transparent alumina coatings were achieved. On-site measurements via UVVis spectroscopy, showed very high reflectance of approximately $96 \%$.

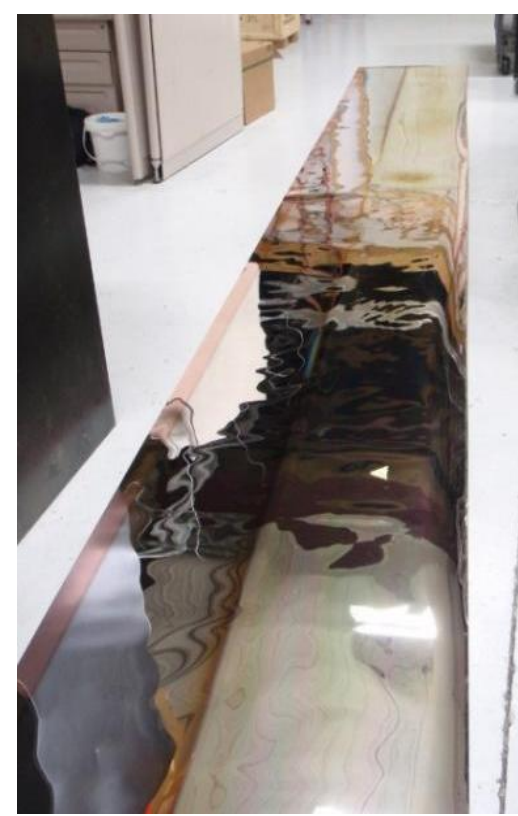

Figure 7. Reflective film. Left side is bare silver film and right side is Alumina coated film
In contrast to these positive results were inconsistent adhesion results for the alumina layer. Adhesion was tested using a tape pull test with tape from ASTM standard D3359 for testing adhesion of coatings. While good alumina adhesion was achieved in certain areas, many samples exhibited visual cracks, flaking material, and/or sheeting off of the alumina layer during tape pull testing.

A summary of the best results can be found in Table 1 . Also included in table 1 are reflectance measurements from commercial glass and film samples for comparison purposes. Deposition rates, ion doses and gas flow rates were varied to try to obtain a film similar to the film grown in phase 1 (090903). The lowest deposition rate tried during this time period was $2.2 \mathrm{~nm} / \mathrm{s}$ and the highest is about $12 \mathrm{~nm} / \mathrm{s}$. Ion energies were varied from $9 \mathrm{eV} /$ atom to $78 \mathrm{eV} /$ atom. In addition, the gas mixture was also varied. 
Table 1.Reflectometer measurements of the best samples from the initial scale up process. $A, B$, and $C$ refer to commercially available mirrors for CSP, where $A$ is a glass mirror and $B$ and $C$ are mirrors on plastic substrates

\begin{tabular}{|c|c|c|c|c|c|c|c|c|c|}
\hline \multirow[b]{2}{*}{ Sample } & \multirow{2}{*}{$\begin{array}{l}\text { \# of e- } \\
\text { beam } \\
\text { sources }\end{array}$} & \multirow{2}{*}{$\begin{array}{l}\text { Dep rate } \\
(\mathrm{nm} / \mathrm{s})\end{array}$} & \multirow{2}{*}{$\begin{array}{l}\text { Drum } \\
\text { speed } \\
\text { (M/min) }\end{array}$} & \multirow{2}{*}{\begin{tabular}{|l|} 
ion \\
source \\
(eVlatom \\
\end{tabular}} & \multirow{2}{*}{\begin{tabular}{|c|}
$\begin{array}{c}\text { Solar } \\
\text { weighted } \\
\text { average }\end{array}$ \\
$(\%)$ \\
\end{tabular}} & \multicolumn{3}{|c|}{ Specularity at $660 \mathrm{~nm}(\%)$} & \multirow[b]{2}{*}{ Adhesion } \\
\hline & & & & & & $7 \mathrm{mRad}$ & $15 \mathrm{mRad}$ & $25 \mathrm{mRad}$ & \\
\hline$A$ & NA & NA & NA & NA & 95.00 & 94.96 & 95.61 & 95.99 & good \\
\hline$B$ & NA & NA & NA & NA & 92.20 & 82.70 & 92.63 & 94.63 & good \\
\hline $\mathrm{C}$ & NA & NA & NA & NA & 91.10 & 8236 & 93.33 & 94.75 & good \\
\hline AS1090903 & 1 & 8.00 & 4.80 & 28.12 & 95.20 & 93.70 & 96.00 & 96.30 & good \\
\hline ASI 111011 & 1 & 12.30 & 4.80 & 16.46 & 91.40 & 90.00 & 93.70 & 94.20 & good \\
\hline ASI 111019 & 1 & 8.00 & 1.20 & 13.68 & 94.90 & 90.30 & 92.30 & 92.60 & good in spots \\
\hline ASI 111114 & 1 & 8.00 & 0.60 & NA & 91.20 & 78.20 & 94.80 & 95.30 & poor \\
\hline ASI 111115 & 1 & 7.00 & 1.50 & 31.64 & 78.80 & 66.00 & 74.50 & 76.10 & good \\
\hline ASI 111117 & 1 & 2.21 & 1.50 & 78.60 & 71.00 & NA & NA & NA & good \\
\hline
\end{tabular}

The sample with the best adhesion from the single source setup was from ASI 11011, which like ASI 090903 used a single strap of substrate wrapped around the cooling drum instead of a roll to roll setup, in which the substrate starts on a source roll and winds through the chamber until it reaches the take-up roll. This well adhered film however was yellow to brown in color and had lower reflectance than films deposited during phase 1. Instead of spending time on the use of a strap, the team focused on a roll to roll setup for commercially viability. By adjusting gas ratios during Alumina deposition, a clear coating was observed instead of a yellow/brown color mentioned earlier. Unfortunately, the adhesion was not consistent, some sections peeling off during adhesion testing.

In addition to adhesion tests, SOC 410 and D\&S refletometer systems were used to measure reflectance and specularity. The D\&S reflectometer is used to measure the specularity of a sample, using three different apertures (7mrad, 15mrad and 25 $\mathrm{mrad}$ ) at $660 \mathrm{~nm}$. The SOC 410 is used to measures the solar weighted average from $335 \mathrm{~nm}$ to $2500 \mathrm{~nm}$.

Of the 5 samples that were measured using the SOC 410, only sample ASI 111019 had a reflectance close to that of ASI 090303 and high reflectance commercial glass mirrors. In addition to a high reflectance, ASI 111019 also had a very good specularity as measured via D\&S. Similar to ASI 090303, only a drop of about 2-3\% was observed from $25 \mathrm{mrad}$ aperature to $7 \mathrm{mrad}$ aperature. However, both were not quite as good as commercial glass mirrors that have only a $1 \%$ loss in reflectance at the different apertures. Both commercial plastic reflective films, B and C, measured for comparison were observed to have lower solar weighted averages and specularity. While the reflectance of ASI 111019 was very high, the sample had mixed adhesion results. Of the 25 areas tested on the sample, 16 passed the tape test and 9 failed.

SEM testing was performed on the film from run ASI 111019, as described below, to help characterize the microstructure of the alumina layer and identify process ad- 
justments best suited for achieving more consistent quality across the web. Results from the testing were incorporated, with the final result of high quality film samples with a consistently transparent and adherent top-coat.

\section{Adhesion Layer and Baseline Film}

SEM (scanning electron microscopy) testing was performed on initial samples at Abengoa's test labs. In Figure 8, the Alumina layer is the upper most layer in the SEM image. The Alumina layer appears to be dense and amorphous; however the layered structure of the barrier layers suggests a failure to form a single dense layer. The layered structure is mostly likely due to the several passes used to deposit the Alumina. The passes are necessary to limit heat loading on the PET substrate. A closer image of the layered structure is necessary to indicate if the Alumina layer is made up of several different layers or if it is a construct of the SEM image. In addition, inconsistent

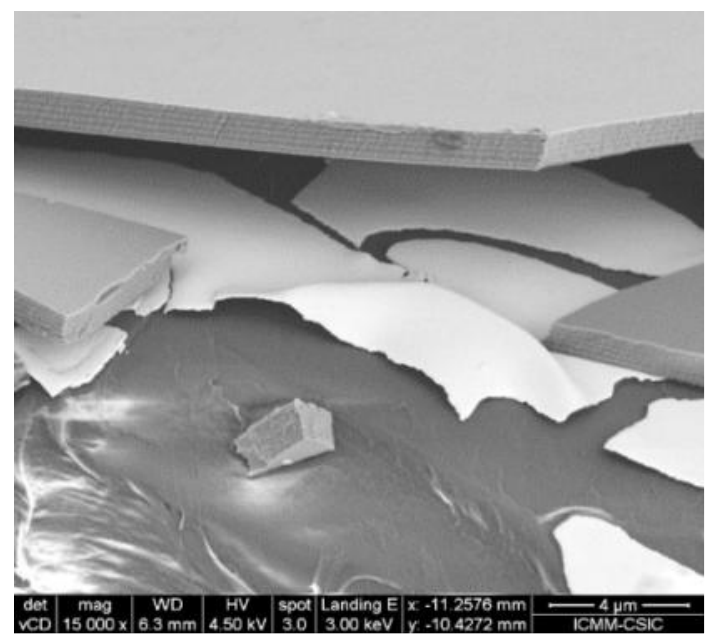

Figure 8. Initial SEM image of film layers. Aluminum oxide is the upper dense light gray region. Metallization is the thin white layer. PET is the bottom dark-gray layer adhesion is observed between the silver and alumina layers, suggesting the importance of an adhesion layer to promote consistent uniform adhesion between these two differing materials. An adhesion layer is deposited with a unique set of process conditions from those for bulk alumina deposition. Bulk deposition then follows, incorporating process conditions, which provide the highest possible deposition rate.

Following incorporation of the adhesion layer and further refinement of process conditions, high quality, highly adhered, and highly reflective film was produced as part of Task 9, the scale up to 36-inch wide films

\subsubsection{Conclusion}

Throughout performance of Task 7, a deeper understanding was gained of how specific process parameters affect film quality. Long multi-hour runs on automatic rate control were successfully achieved, using the quartz crystal monitor to measure the deposition rate. Preconditioning of the alumina was shown to minimize deposition rate spikes and reduce e-beam spitting. Initial samples showed high reflectivity, approximately $96 \%$ according to initial on-site tests, with inconsistent adhesion. SEM testing of the film microstructure showed an appropriately dense amorphous alumina structure, but highlighted the inconsistencies in adhesion of the alumina and silver layers. An adhesion layer with a unique set of process conditions was incorporated into the film production process during the scale up to 36-inch wide mirror coating. 


\subsection{Task 8: Test end-Hall Ion Source}

\subsubsection{Summary}

The purpose of Task 8 was to evaluate a unique end-Hall ion source for ASRM production. End-Hall lon Sources are desirable due to their relatively low cost and low maintenance requirements; however, the majority of these units provide insufficient power for ASRM production. Following Phase 1, an innovative new higher-power end-Hall ion source was identified with good potential for use with the process. The purpose of the task was to determine whether this unique design could successfully be integrated as part of the IBAD process. Unfortunately, the end-Hall ion source failed during operation, as a result of overheating of the ion source anode. The end-Hall was tried twice and experienced similar failures. Due to time restrictions, the end-Hall ion source was replaced with a gridded ion source which worked well during the first phase of the project.

\subsubsection{Task Results}

\section{End-Hall Testing}

The end-Hall ion source, Saintech ST3000, is a unique, water-cooled unit, allowing higher ion source powers than typical end-Hall sources. All vendor input and data indicated good potential for ASRM production.

After installation in the DTI chamber, the unit failed during initial testing. When power was raised to desired operating levels, a melt spot developed on the anode. The vendor reported that higher cooling water flows were needed the powers required by the project. A replacement anode was sent and testing resumed.

A second, similar failure occurred during the next set of testing even though cooling water flow was above the recommended flow rate. Anode damage occurred as power was raised to desired operating levels. Subsequent discussions with the vendor indicated that build-up of the dielectric aluminum oxide onto the open-faced anode was likely limiting heat transfer away from the unit and causing overheating. The team determined that back-spray of the dielectric onto the ion source during deposition is unavoidable; high target deposition rates make mitigating measures such as additional shielding, or shifting of the ion sources, insufficient to protect the anode. As a result, the end-Hall ion source was disqualified, along with any ion source incorporating an open face anode.

\section{lon Source Choices}

Following the failure of the end hall ion source, the gridded ion source, which successfully produced film during phase 1 , was reintegrated into the project. The team investigated a variety of alternative ion sources including anode layer (ALS) sources, radio frequency (RF) sources, and various different gridded ion source and end-Hall ion source options. 
All analysis confirmed that the gridded source remains the most optimal ion source for this type of IBAD process. Gridded sources are available at high power, unlike end-Hall sources, and allows for more control of charged particle direction, energy and density. In addition, the gridded ion source anode is not exposed, unlike endHall and ALS, which allows for better application to deposition of dielectric materials.

As identified in Phase 1, the disadvantage of a gridded ion source is increased maintenance requirements when the grids become contaminated. However, during the renewed combined phase 2 and 3 investigation, a new gridded ion source feature was identified that serves to mitigate maintenance requirements. A third grid is incorporated into select models, which serves like a screen, protecting the working grids from contamination. This allows long runs before servicing are required, and the third grid can be swapped out between runs for scouring. The three-grid model gridded ion source was therefore selected as the ion source of choice for scale-up and was successfully implemented during the remainder of the phase. The disadvantage of the three-grid model was the collimated beam which is discussed in Task 9.

\subsubsection{Conclusions}

The high-power end-Hall ion source was disqualified for ASRM production following failure during testing. Aluminum oxide back-spray coating the open-faced anode was found to limit heat transfer and cause the anode to melt. Investigation of alternative ion sources revealed gridded ion sources, the type successfully used in the first phase of the project, to be best suited to ASRM production. New three-grid models help minimize the maintenance requirements of gridded sources, which are typically greater than those of an end hall ion source.

\subsection{Task 9: Upgrade to 36-inch Width}

\subsubsection{Summary}

The objective of Task 10 was to scale up the system from a 12-inch wide to a 36inch wide deposition zone. The 36-inch width approaches the width needed for commercial production. Scaling up the width to 36 inches allows for testing of interplay between adjacent e-beam guns and characterization of coating uniformity across a wide web. One of the major concerns with the system expansion was the electromagnetic interference or cross-talk between adjacent e-beam sources. Using a Gauss meter to test the cross-talk between the e-beam sources, little to no magnetic interference was observed. The lack of cross-talk allows for the e-beam systems to be place in a side by side configuration versus a "head-to-tail" configuration. In addition to e-beam sources installed, additional ion sources, gas lines, water lines, quartz crystal microbalances and a moveable baseplate were installed. 


\subsubsection{Task Results}

\section{E-beam Orientation Magnetics Testing}

The first step in the scale-up was to determine the optimal orientation for the electron beam guns, taking into account the magnetic interplay between neighboring units. Results were incorporated into the designs generated as part of Task 1.

Electron beam guns operate by bending the path of emitted electrons using a series of fixed and electro-magnets. When placed side by side, the magnetic fields can interfere with one another, creating a phenomenon known as "cross-talk". To minimize this interference, designers typically recommend that the e-beams be rotated 180 degrees from one another, in a "head-to-tail" configuration, and that mu metal sheets be placed between them to shield the magnetic effects. However, the "head-to-tail" configuration is sub-optimal for the project; it pushes the ion sources out further from the e-beam sources, meaning a less direct line of sight to the deposition zone, and subsequently, less adequate densification of the films.

This made it necessary for the team to determine whether a "head-to-head" ebeam gun orientation could be used, or whether the magnetic cross-talk issues would be too great in this configuration. To make the determination, bench-top magnetics tests were performed. Two ebeam guns were placed side by side in both "head-to-head" and "head-to-tail" orientations, with varying numbers of $\mu$ metal sheets placed between them, Figure 9. The electromagnetic sweeps were turned up in steps to maximum power. Magnetic measurements were taken with

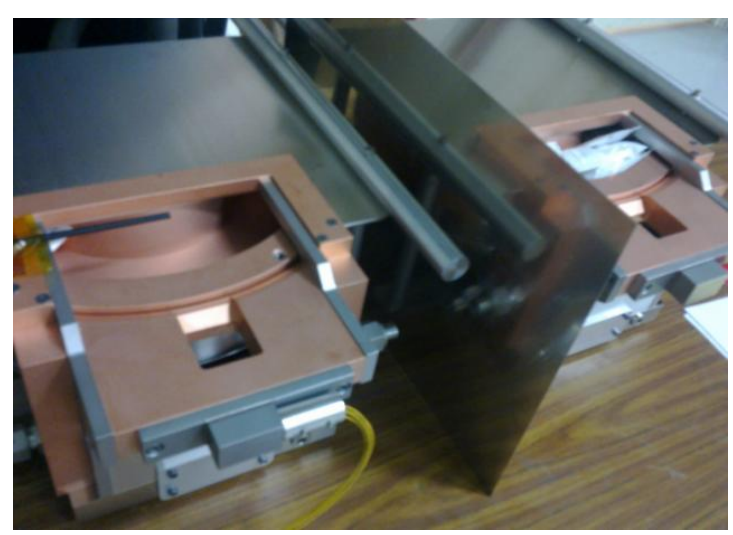

Figure 9. E-beam magnetic field test with a piece of $\mu$-metal placed in between the sources a gauss-meter at each interval, to determine the electromagnetic effects of each gun on the other.

The tests revealed a number of surprising results. The effect of the $\mu$-metal sheets, which are supposed to act as magnetic shields between the guns, was found to be nearly negligible. Data collected from the magnetic measurements in the "head-tohead" orientation indicated that very little interference existed between the two ebeam sources, just as the team had hoped. An additional break-through was made when consultant Richard Swisher suggested that placing a mild steel plate beneath the guns would carry the magnetic field lines away from the guns, thus reducing the inherent interaction between them. Designs were updated to reflect the "headto-head" e-beam orientation and a mild steel baseplate was specified in place of a stainless steel one. 


\section{Equipment Installation}

Equipment was installed in the DTI chamber during January and February 2012. Electron beam guns, power supplies, ion sources, and quartz crystal monitors were installed in the system. Additional water lines were plumbed to provide for the additional cooling water capacity needs of the system, and a DI (deionized) chilled water system was installed to avoid contamination of the electron beam cooling lines (which can affect the operation of the units).

In April 2012, webcams were added to the inside of the chamber to help see inside the e-beam melt. The cameras worked under vacuum but were not able to give required resolution of the melt and were later replaced with mirrors. In addition, shields were added in between the e-beam and ion source to limit deposition on the ion sources.

\subsection{Task 10: Produce and Test 36-inch Wide Samples}

\subsubsection{Summary}

The objective of Task 10 was to complete a series of 36-inch width production runs to demonstrate production stability and production target costs. Focuses for the task included running multiple e-beams in parallel without interference, multiple pass operations, and coating uniformity across a wide web. Reflective material produced during the runs was to be used for performance and durability testing and limited reflector fabrication. The reflectivity goal for material produced during the Task was $95 \%$ or greater.

In several cases greater than 95\% reflectance was achieved, however adhesion was still an issue. In addition, the full 36-inches width was not achieved due to the collimation of the ion beam sources. The maximum width produced was about 32inches wide. In addition to mixed adhesion issues, warping and crazing were observed.

\subsubsection{Task Results}

In January of 2012, installation of the deposition equipment to increase the deposition width to 36 inches began. From March to early October 2012, mirror coatings were deposited using two or more e-beam sources. At first, depositions were conducted using one e-beam source and one ion source to try to reproduce results from the previous year since the system was out of commission for the better part of three months. Once a baseline was established, an additional e-beam and ion source were installed to continue the scale up. About three months were spent reaching a baseline with the two source system before the addition of more sources to reach the 36-inch wide deposition zone. In November 2011, SEM images revealed a lack of adhesion between the Silver and Alumina layers. After attempting 
alternate approaches, the project determined the need for an adhesion layer, which was developed and then added in April 2012.

To incorporate a $3^{\text {rd }}$ e-beam system, another CV-14 power supply had to be purchased and installed. One CV-14 controlled two e-beam sources and one controlled the third e-beam source. In addition to adding another e-beam source, an additional two ion beam sources were installed into the system for a total of four ion beam sources. Additionally, the sputter sources were adjusted to increase the deposition zone to 36 -inch.

The goal was to successfully produce 36 -inch wide film with $>95 \%$ reflectivity and with good adhesion. In early June 2012 after the initial three source deposition it was determined that the three grid ion sources were too collimated and thus the team was unable to obtain uniform ion beam coverage for the 36-inches wide film. To get more uniform coverage, the ion sources were tilted towards the middle thus the edges were without ion coverage. This configuration change moved the expected depositions area to around 32-inches wide instead of 36-inches. The next several months were spent trying to obtain consistent adhesion with mixed results. Very good adhesion was found on some samples and poor on others even though the conditions were similar. The results for some of the better films are located in Table 2. In comparison with earlier depositions using the 1 source setup, the reflectance was higher. Several runs had solar weighted averages around $95 \%$ with good adhesion, which is greater than measured on many commercial glass mirrors or any film samples. The specularity of the films however were not as good as the commercial glass mirror but were comparable to the commercial films. The best film grown during this phase was ASI 120801, which was sent to NREL for further testing. In addition to high reflectance, the adhesion on ASI 120801 was very good. Samples ASI 120730 and ASI 120731 also had high reflectance but the adhesion was poor even though the conditions were very similar.

After investigating the adhesion inconsistency it was found that about a month after the adhesion layer was used that the procedures for applying the adhesion layer were inadvertently changed. The change in procedure may have deposited a thinner adhesion layer than desired. The team believes the adhesion layer, when properly applied, provides very good adhesion, however due to time limitations there is not enough data to sufficiently support the theory.

In addition, while upgrading the deposition zone from 12-inch to 36-inch, the team began noticing crazing (subsurface cracking) effects on the web. The crazing was worse in areas without significant ion beam coverage. The crazing is most likely due to the need to relax tensile stress in the alumina thin film. By tilting the ion sources, the crazing was minimized in the center but was still apparent in some cases. To reduce the crazing in certain areas, either the deposition rate had to be reduced or the ion assist had to be increased. Unfortunately a lower deposition rate dramatically increases the cost in a production environment and with an increase in ion dose the web warps and at times will burn through the PET. Even at the high 
drum speeds, the web warping is instantaneous at high ion beam powers. The web drive also has issues at high speeds, constantly needing to be reset. During the program reset, the drum was stopped thus the web was put under considerable heat load and can cause the web to severely warp and melt. To reduce this issue, a slowdown zone was added to the pass turnaround; however given a total of around 30 passes this can be very tedious. The slowdown sections become severely warped and prone to cracking.

Table 2. Results from the most promising films grown as a part of Task 9. The highlighted sample was sent to NREL for additional testing, in Task 14. As in Table 1, A, B, and C refer to commercial mirrors, where $A$ is on glass and $B$ and $C$ are on plastic

\begin{tabular}{|c|c|c|c|c|c|c|c|c|c|}
\hline \multirow[b]{2}{*}{ Sample } & \multirow{2}{*}{$\begin{array}{l}\text { \# of e- } \\
\text { beam } \\
\text { sources }\end{array}$} & \multirow{2}{*}{$\begin{array}{l}\text { Dep rate } \\
(\mathrm{nm} / \mathrm{s})\end{array}$} & \multirow{2}{*}{\begin{tabular}{|l}
$\begin{array}{l}\text { Drum } \\
\text { speed }\end{array}$ \\
(M/min)
\end{tabular}} & \multirow{2}{*}{\begin{tabular}{|l} 
ion \\
source \\
(eV/atom \\
\end{tabular}} & \multirow{2}{*}{ 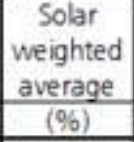 } & \multicolumn{3}{|c|}{ Specularity at $660 \mathrm{~nm}(\%)$} & \multirow[b]{2}{*}{ Adhesion } \\
\hline & & & & & & $7 \mathrm{mRad}$ & 15 mPlad & $25 \mathrm{mRad}$ & \\
\hline $\mathrm{A}$ & NA & NA & NA & NA & 95.00 & 9496 & 95.61 & 95.99 & good \\
\hline$B$ & NA & NA & NA & NA & 92.20 & 82.70 & 92.63 & 94.63 & good \\
\hline C & NA & NA & NA & NA & 91.10 & 82.36 & 93.33 & 94.75 & good \\
\hline ASI 120201 & 1 & 5.75 & 1.50 & 1259 & 93.10 & NA & NA & NA & poor \\
\hline ASI 120511-1 & 2 & 10.68 & 1.50 & 0.82 & 9280 & NA & NA & NA & good \\
\hline ASI $120511-5$ & 2 & 700 & 1.50 & 1.23 & 93.60 & NA & NA & NA & good \\
\hline ASI 120607 & 3 & 5.23 & 3.00 & 1.67 & 95.40 & NA & NA & NA & fail \\
\hline ASI 120625 & 3 & 4.75 & 1.50 & 1.84 & 9490 & NA & NA & NA & good \\
\hline ASI 120626 & 3 & 6.68 & 3.50 & 27.54 & 94.80 & NA & NA & NA & good \\
\hline ASI $120717 a$ & 3 & 11.90 & 3.50 & 593 & 94.80 & 89.63 & 94.05 & 94.88 & good \\
\hline ASI 120719 & 3 & 11.00 & 3.50 & 14.24 & 9487 & 80,99 & 87,36 & 89.03 & small delam \\
\hline$A S 1120720 a$ & 3 & 9.40 & 3.50 & 13.98 & 95.20 & NA & NA & NA & small delam \\
\hline $\mathrm{ASI} 120720 \mathrm{~b}$ & 3 & 8.30 & 350 & 18.94 & 94.70 & NA & NA & NA & poor \\
\hline ASI $120727 a$ & 3 & 8.00 & 3.50 & 13.10 & 95.50 & NA & NA & NA & good \\
\hline ASI $120727 \mathrm{~b}$ & 3 & 10.00 & 3.50 & 10.51 & 95.60 & NA & NA & NA & good \\
\hline ASI 120730 & 3 & 10.88 & 3.50 & 7.40 & 95.30 & NA & NA & NA & poor \\
\hline ASI 120801 & 3 & 10.00 & 3.50 & 12.32 & 95.60 & 83.90 & 9260 & 93.60 & good \\
\hline
\end{tabular}

Using a Nikon metallurgical microscope, images of four different deposition runs were captured. In each case several pinholes were observed, ranging in size from 1 um to $>5 \mu \mathrm{m}$. In addition, the sample collected during the first phase, ASI 90903 had severe silver tarnishing. A closer image of ASI 90903 reveals corrosion around pinholes and cracks, shown in Figure 10. Furthermore, blister-like defects are observed throughout the sample. The cracks and blister-like defects may have been caused by handling issues given that the sample has been handled for more than 3 years before images were taken. Samples ASI 120511, ASI 120626 and ASI 120801 appeared to have various degrees of cracking, ASI 120511 having the most severe cracks. The crack formation on ASI 120626 and ASI 120801 appeared to be subsurface cracking. The pinholes and subsurface cracking could cause issues with corrosion in the future as observed in ASI 90903. Using a sulfur solution or sulfur gas might be a way to indicate the mechanisms of corrosion for these films. 


\subsubsection{Conclusion}

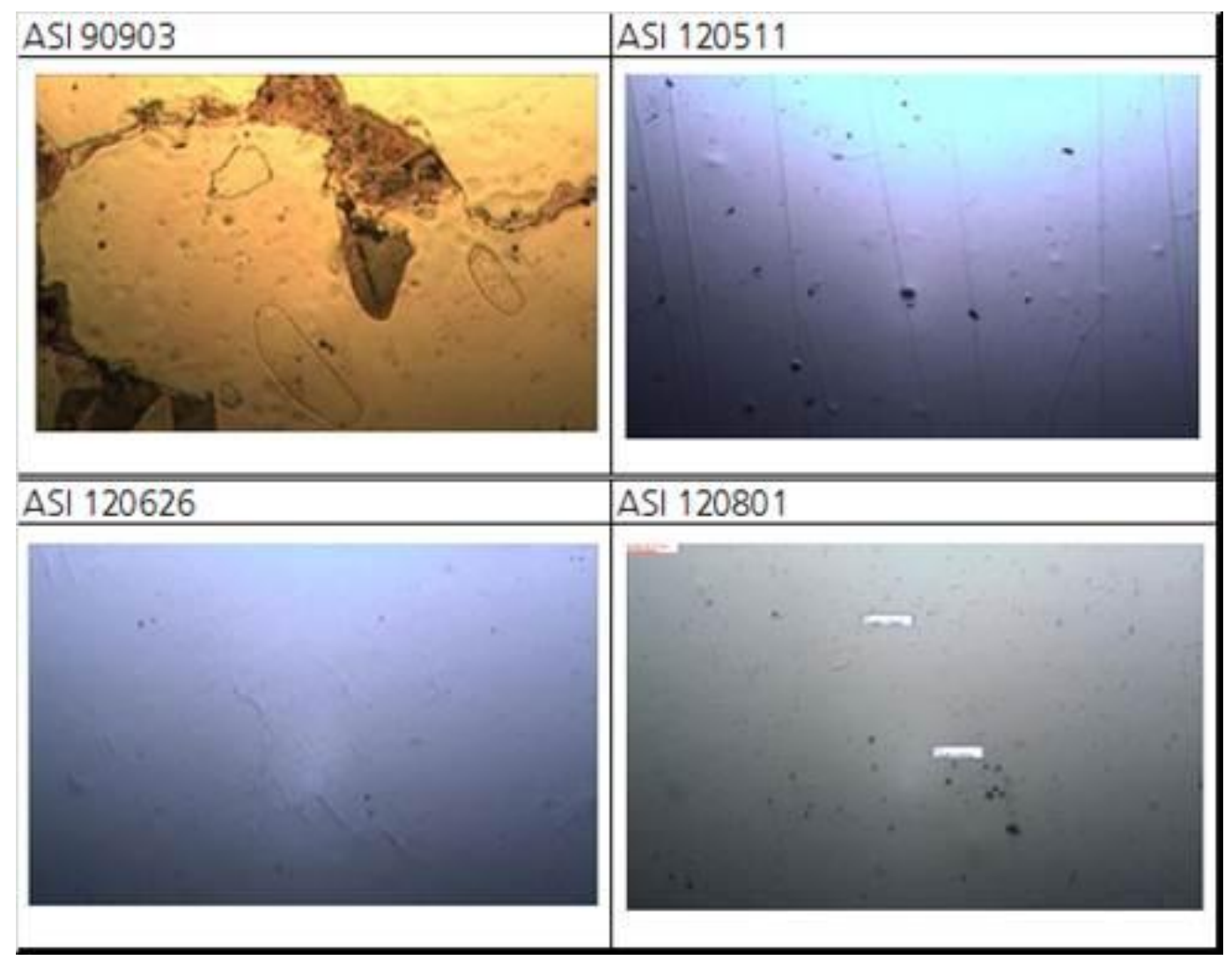

Figure 10. 20x microscope images of 4 different runs including the sample grown at Marion (090903). Note that the color is an artifact of the microscope and not real.

In conclusion, the team was able to successfully expand the deposition area and create a well adhered, high reflectance sample for further testing. The three grid ion sources allowed a longer running time, but collimated the ion beam so a 1 meter wide mirror film was not possible with the current configuration. The areas outside the ion beam assisted region were prone to crazing; the areas inside the ion beam assisted region were prone to warping. In addition, unfortunate issues with creating the adhesion layer prevented more consistent results. In addition, images from early experiments in phase 1 show the existence of pinholes consistent with the most recent films created. The pinholes would be a pathway for corrosion, indicating the need for denser layers.

\subsection{Task 11: Upgrade to Full Width}

\subsubsection{Summary}

The objective of Task 11 was to scale up the system to the full 48-inch wide deposition zone. Film production at this width demonstrates the feasibility of the process at full commercial production widths. Interplay between adjacent e-beam guns 
must be managed and reasonable coating uniformity must be maintained across the full web.

\subsubsection{Task Results}

Due to limitations of the ion beam configuration and distribution, the team was not able to reach the 48 inch wide goal.

\subsection{Task 12: Produce and Test 48-inch Wide Samples}

\subsubsection{Summary}

The objective of Task 12 was to complete a series of full 48 -inch width limited production runs to demonstrate production stability and production target costs. This scale-up provides the final step in proving the viability of scale-up of the process to full width. Focuses for the task include running four e-beams in parallel without interference, multiple pass operations, deposition uniformity, and substrate temperature control. The reflectivity goal for material produced during the Task is $95 \%$ or greater.

\subsubsection{Task Results}

Due to limitations of the ion beam configuration and distribution, the team was not able to reach the 48 inch wide goal.

\subsection{Task 13: Structural Facet Panel Testing}

\subsubsection{Summary}

The objective of Task 13 was to investigate light-weight, high-strength structural facet backing panels. In order to realize the wide variety of potential ASRM benefits an appropriate backing panel must be identified. The film alone is pliable and lacks form, so a facet panel must provide rigid structure while capitalizing on the film's light weight and flexibility. Initial analysis conducted by ASI indicated a significant possible reduction (>30\%) in the concentrator framing structure based on integration of structural reflector designs. However, suitable candidate materials must be demonstrated in order to establish a viable deployment of the ASRM. Key properties that the facet material must demonstrate include rigidity, small slope error, resistance to creep, reasonable cost, and the ability to be manufactured in the required parabolic form. 


\subsubsection{Background}

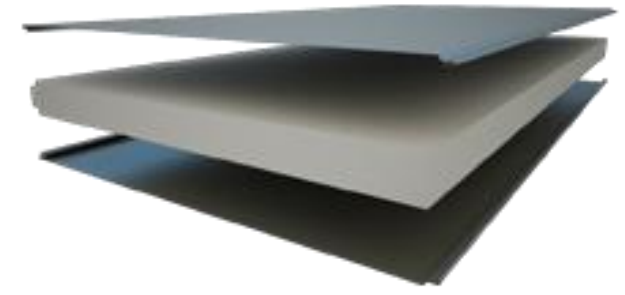

Figure 11. Sandwich Composite Panel Structure

Structural sandwich composites, a type of material commonly used in aerospace, wind power, and architecture, provide precise shape in combination with high strength and low weight / cost. These composites consist of a light-weight core material, for example PVC foam or aluminum honeycomb, sandwiched by aluminum sheets or other materials, Figure 11. The combined materials display stiffness and strength magnitudes greater than any of the materials alone and at low costs.

A 1998 study by Sandia National Labs highlighted the potential of foam-core sandwich composites to provide excellent structural and slope error characteristics, as well as acceptable costs, and also highlighted limitations based on degradation of the core material during extended exposure to high desert temperatures. Foam core composite reflector panels have also been investigated by other groups (Sandwich Construction Solar Structural Facets by Diver and Status of Glass Reflector Technology for Heliostats and Concentrators by Stone).

All previous studies showed promising potential for the use of composite structural facets in solar energy applications; however, a technically and economically viable configuration had not yet been demonstrated. Testing of potential materials would be required in order to validate a path forward for implementation of the ASRM.

\subsubsection{Results}

Evaluation of the facet panels was divided into four stages. These include initial material investigation, coupon testing, small prototype panel testing, and finally full size prototype panel testing. Each step incorporates down-selection to the most promising candidate materials.

The primary criteria for evaluation of the materials were

- Reasonable cost

- Low slope error (less than 2 mrad RMS)

- Ability to maintain performance and shape for 30+ years under the high temperatures and weather conditions displayed in the solar field. 


\section{Material Investigation}

Investigation of core materials was the first stage of the facet panel investigation. The challenge was finding materials of low enough cost that would optically perform in a solar field for the life of the plant. The material must be dimensionally stable in extended operating temperatures up to $60^{\circ} \mathrm{C}$. For this reason, any material with a transition glass temperature $(\mathrm{Tg})$ less than $70^{\circ} \mathrm{C}$ was deemed an unlikely candidate. The glass transition temperature is the temperature at which a material exhibits a glass-like, viscous behavior that is prone to creep.

More than twenty different core materials were evaluated; all but three were eliminated based on issues with Tg, thermal stability, cost, mechanical stability, and durability. Physical properties and previous literature indicated that these materials presented the greatest likelihood for reasonable cost and resistance to thermal degradation. First order cost estimates from the analysis showed that it is possible for a suitable composite panel to be fabricated economically (including face-sheets, adhesive and labor).

\section{Coupon Testing}

Coupon testing was the second stage of the facet panel investigation. In this test small (inches wide) coupon samples were tested for dimensional stability at high temperatures. The test was not intended to fully validate materials for use in composite panels, but to eliminate unsuitable materials and identify core materials that warrant further testing.

In the test, small 6-inch $\times 3$.5-inch $\times 0.5$-inch composite samples were loaded with weights to simulate shear stresses in the core of a full size panel and placed in a test oven in temperatures up to $70 \mathrm{C}$. First, core materials were bonded to aluminum face sheets using Hysol EA9394 adhesive and placed in a three point bending scenario in a modified version of the method for determining core creep of laminated panels defined in ASTM C481 (see Figure 12). The weight applied was twice that needed to replicate stresses on a full size panel under its own weight, assuming a 5 foot cantilever. This simulated not only the weight of the full panel but also some wind loads.

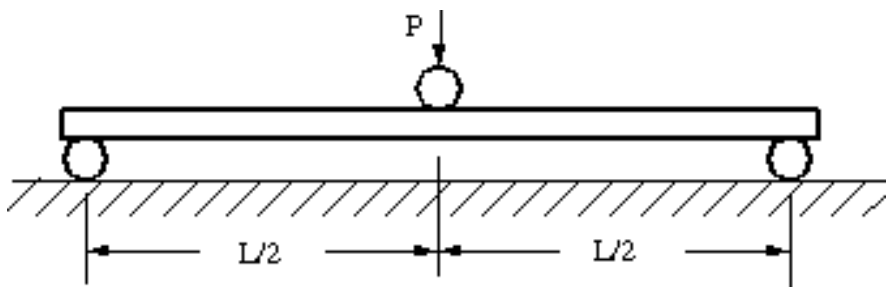

Figure 12. Coupon Sheer Stress Setup

The weighted materials were placed in a small test oven at $60^{\circ} \mathrm{C}$ for 60 days. Materials which survived the test without significant deflection were then tested for an additional $30-40$ days at $70^{\circ} \mathrm{C}$. The maximum temperature expected to be experi- 
enced by a facet panel in the solar field is $60^{\circ} \mathrm{C}$, while $70^{\circ} \mathrm{C}$ represents an even more rigorous test for indicating material creep at high temperatures.

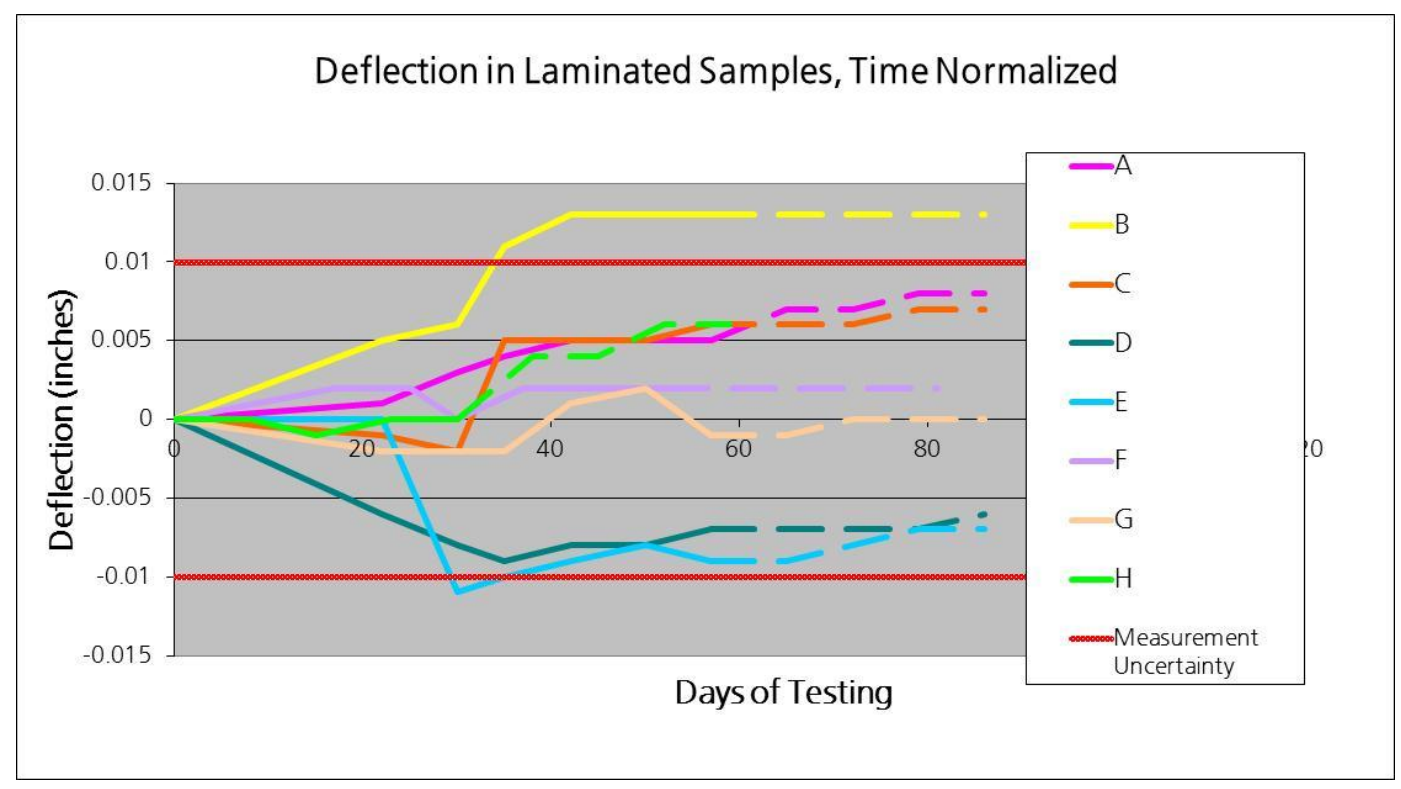

Figure 13. Caliper measurements of the deflection in laminated samples. Solid lines indicate testing at $60^{\circ} \mathrm{C}$, dashed lines indicate testing at $70^{\circ} \mathrm{C}$

The deflection of the samples was measured using both the laser radar (LR) and a set of calipers at various points throughout the 90 day testing period. The results are presented in the Figure 13. Of the laminated composite samples, only the sample B (yellow line), a polystyrene foam, showed creep beyond the uncertainty of the measurements and was eliminated. Sample E showed a deflection on the margin of the measurement uncertainty, indicating the need for further investigation, and this option was put aside. All deflections occurred during the $60^{\circ} \mathrm{C}$ test period and remained unchanged during $70^{\circ} \mathrm{C}$ testing.

The results of the coupon sample testing were encouraging, revealing the potential of a wide variety of materials to withstand the high heat environmental conditions required for a solar facet panel. Only sample B was disqualified during these tests after showing significant creep, consistent with previous findings in the literature that indicate potential instability in polystyrene cores.

Small Scale Prototype Panel Testing

Small scale prototype panel testing is designed to evaluate panel options optically, structurally, and for durability. Panels at the size of current parabolic glass mirrors (1.6-m $\times 1.2-\mathrm{m}$ ) were selected for easy comparison to existing glass mirrors and because they can fit into an environmental testing chamber. Three of the materials identified as most promising during the previous stages were selected for further investigation. 
These panels underwent the tests below:

1. Optical performance evaluation

2. Accelerated environmental testing

3. Optical evaluation to determine effects of the environmental testing

4. Hail impact testing

Optical evaluation of the panels was performed using the laser radar. A 2 mrad or lower RMS slope error was required for panels to pass. Panels were profiled and compared to an ideal parabola and RMS slope error was calculated.

Following initial optical analysis, the NREL environmental chamber was used for accelerated weathering testing. The panels were supported and loaded in the test chamber to mimic the shear and bending loads experienced in the field. During environmental testing, samples were cycled daily on weekdays between ambient and $60^{\circ} \mathrm{C}$ temperatures.

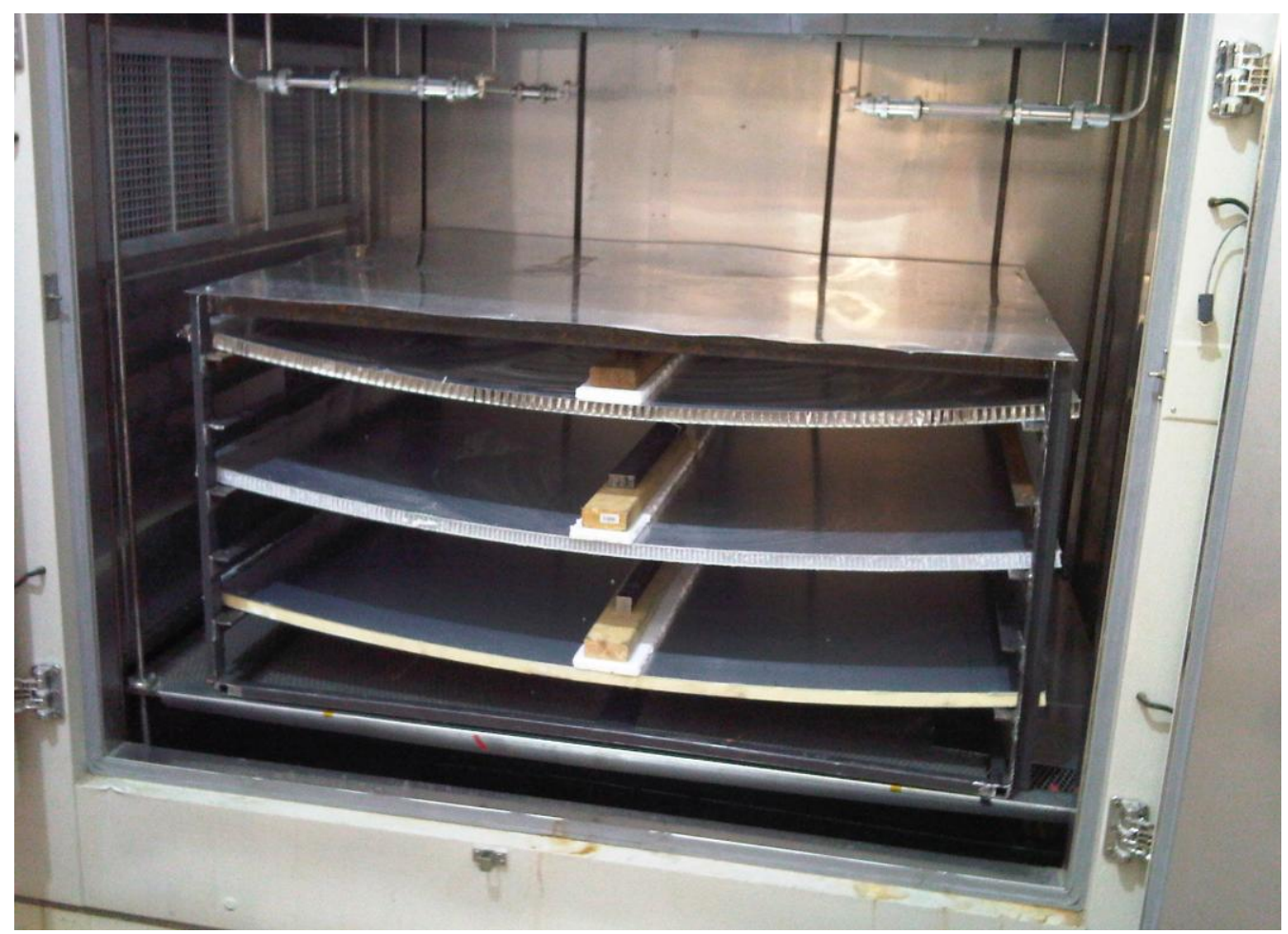

Figure 14. Panels in Elevated Temperature Chamber

Panels underwent a total of 964-975 hours of environmental testing. Of the three different panels optically tested, only one passed the elevated temperature test with a change in slope of $0.33 \mathrm{mrad}$. The other two core materials showed measurable deformation following exposure, $1.02 \mathrm{mrad}$ and $0.96 \mathrm{mrad}$ respectively. However, the adhesive used by the manufacturer to laminate both of these panels was found to have had a $\mathrm{Tg}$ below $60^{\circ} \mathrm{C}$. Therefore the increase in creep could have been due 
to the adhesive which makes results inconclusive and requires that additional testing be performed before fully disqualifying the cores.

Finally, the panels were subjected to hail impact tests using NREL's hail gun. Panels were cut down to 20 -inch $\times 20$-inch size and laminated with a reflective film. A pass was achieved if the hail impact to the back of the panel did not cause significant dimpling on the face, nor any disbond of material or significant tearing of the facesheet. The panels were tested with two different sized hail balls, 1 " and .75" diameter, both impacting the samples with a velocity between 50 and 55 miles per hour. All panels successfully passed the hail tests and are expected to hold up structurally following hail impact.

\section{Full Size Prototype Panel Testing}

The final step of the facet panel exploration was production of full size facet panels. Panels were constructed of the three most promising candidate cores from earlier investigations. Facet panel candidates were tested optically, structurally, and for durability. The panel size chosen represents the half-aperture of a $7.5 \mathrm{~m}$ aperture collector.

The panel dimensions were $3.7 \mathrm{~m} \times 1.2 \mathrm{~m}$, curved to form a $7.5 \mathrm{~m}$ aperture parabola. The panels underwent three sets of tests:

- Optical accuracy evaluation

- Outdoor Testing

- Structural testing

\section{Optical Accuracy Evaluation}

Initial prototypes were examined for optical accuracy using surface point enhanced laser radar (SPE) and high density laser radar (HDLR) scans. The first set of panels showed errors of 2-3 mrad, out of tolerance with the required less than 2 mrad optical error. Laser radar measurements of the tool used to produce the panels enabled the company to re-machine it within a tighter tolerance. Resulting panels showed acceptable slope errors from $0.5 \mathrm{mrad}-1.8 \mathrm{mrad}$. Faint print-through was observed on one of the panels, however, it is expected that print-through will not persist during commercial production. The cause of the print-through is likely the vacuum sealing techniques used for prototyping and the effect should be eliminated or minimized by commercial pressure bonding techniques. Thicker facesheets are a secondary alternative for eliminating this effect.

\section{Outdoor Testing}

The panels were then subjected to outdoor testing. Both an ambient condition test and a direct sunlight exposure test were performed. The pass qualification was that expected operating conditions cause a less than $2 \mathrm{mrad}$ slope change in the panel.

Ambient condition testing was commenced first. In the field, panels are expected to survive $36^{\circ} \mathrm{F}\left(20^{\circ} \mathrm{C}\right)$ temperature changes without exceeding the slope error limit. In the ambient test, the air temperature varied $15^{\circ} \mathrm{F}$, between $55^{\circ} \mathrm{F}$ and $70^{\circ} \mathrm{F}$, 
over a single day. The laser radar periodically measured the location of tooling balls placed across the surface of each composite panel, in order to determine any changes to the panel's slope.

One of the cores was not tested because of its poor performance in NREL elevated temperature tests, so the remaining testing was for the two remaining cores, refered to as panel $A$ and panel $B$ below. After a temperature change of $15^{\circ} \mathrm{F}$, panel $A$ showed a slope change of $1.5 \mathrm{mrad}$. Panel $B$ showed changes of approximately 0.1-0.2 mrad, which is within the error of measurement uncertainty. Extrapolating these results to a $36^{\circ} \mathrm{F}$ change, the panel $\mathrm{A}$ failed the ambient temperature test, with expected deformations above 3 mrad. Panel B passed, with very small expected deformations, in the range of $0-0.53 \mathrm{mrad}$.

The direct sunlight exposure test was performed next. Plastic solar reflector material was wet laminated onto the surface of each panel. The front-face (reflective surface) of the panels was exposed to direct sunlight and the temperature difference between the front and back facesheets of the panels was measured using thermocouples. A large temperature differential between the front and back facesheets can cause differential expansion in each of the sheets, thus causing a distortion in the panel shape and additional shape error.

After the temperature stabilized, the temperature difference between the front and back facesheets of panel B was only approximately $0.3^{\circ} \mathrm{F}$. This demonstrates excellent heat conductivity through the core material. This panel passes the direct sunlight exposure testing. It is not expected to deform from differential heating.

For Panel A, a more significant temperature differential of $3^{\circ} \mathrm{F}$ was measured between facesheets, causing distortion in the panel shape and unacceptable loss of optical accuracy. In this case, the insulative properties of the panel are detrimental to its use in a solar collector.

\section{Structural Testing}

Structural testing was performed on the panels. Panels were subjected to a 3-point bending test, with a test panel section spanning 39 or 54 inches across two sawhorses, suspending a weight bucket from a stringer bonded to the panel (Figure 15). The deflection of the panel was measured and the panel was unloaded and inspected for signs of permanent deflection using the laser radar.

The target weight for each panel

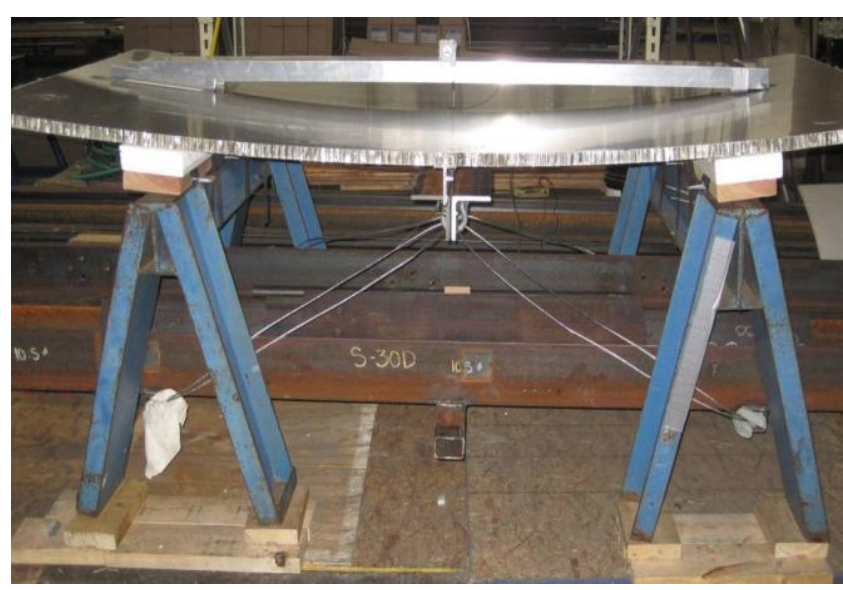

Fiqure 15. Structural Test Setup 
was based upon a pressure load to the facesheet due to wind-loading. The target loads were 1,050-lbs for two of the panels, and $963 \mathrm{lbs}$ for the other panel. The reason for the smaller weight used in the ALHX testing is because of a modification to the test setup to a 54-inch span instead of the 39-inch span. In all cases, the equivalent pressure load remained the same.

During structural testing the adhesive between the stringer and face sheet failed for the first panel, causing unintended stress concentrations, resulting in the disbonding of the facesheet in several locations on the panel. The test setup was modified to incorporate a higher strength epoxy. Testing of the remaining panels was then completed with the new setup, but the first panel testing will have to be repeated on a new panel at a future date.

The one panel survived not only the 1,050-lb, but also loading $25 \%$ above the design load (1,300-lbs) with no permanent deformations. The other tested panel survived the design load with no permanent deformation; however when the load was increased $25 \%$ above the design load, to 1,204-lbs, the panel showed slight permanent deformation of 0.008 inch over the 91 -inch length of the panel. Based on these results, the two panels that could be tested both pass structural testing. Results for the third are inconclusive, based on a failure of the test setup.

\subsubsection{Conclusions}

The three most promising structural facet panel materials were down-selected from the more than twenty materials investigated as part of Task 11. Prototype panels were produced and underwent accelerated weathering and hail testing at NREL, as well as optical, structural and outdoor testing at ASI facilities. One core material showed very good performance, passing every one of the tests performed. One promising material was unable to maintain shape tolerances when exposed to direct solar radiation on its front surface. A third promising material changed shape during high temperature accelerated weathering tests; however this may have been due to the adhesive used to bond it, as opposed to the failure of the material itself. Additional testing will have to be performed at a future date to obtain conclusive results for this material.

The positive results for the best panel prove that composite structural panels can be produced at effective cost with superior optical characteristics and the ability to withstand the high heat conditions of a solar field. This demonstrates a path forward for commercial solar implementation of reflective films. 
The strength and light weight of the ASRM and composite panel is expected to allow more than $33 \%$ reduction in the collector structure, with attendant LCOE reductions. This light-weight characteristic is clearly demonstrated in Figure 16.

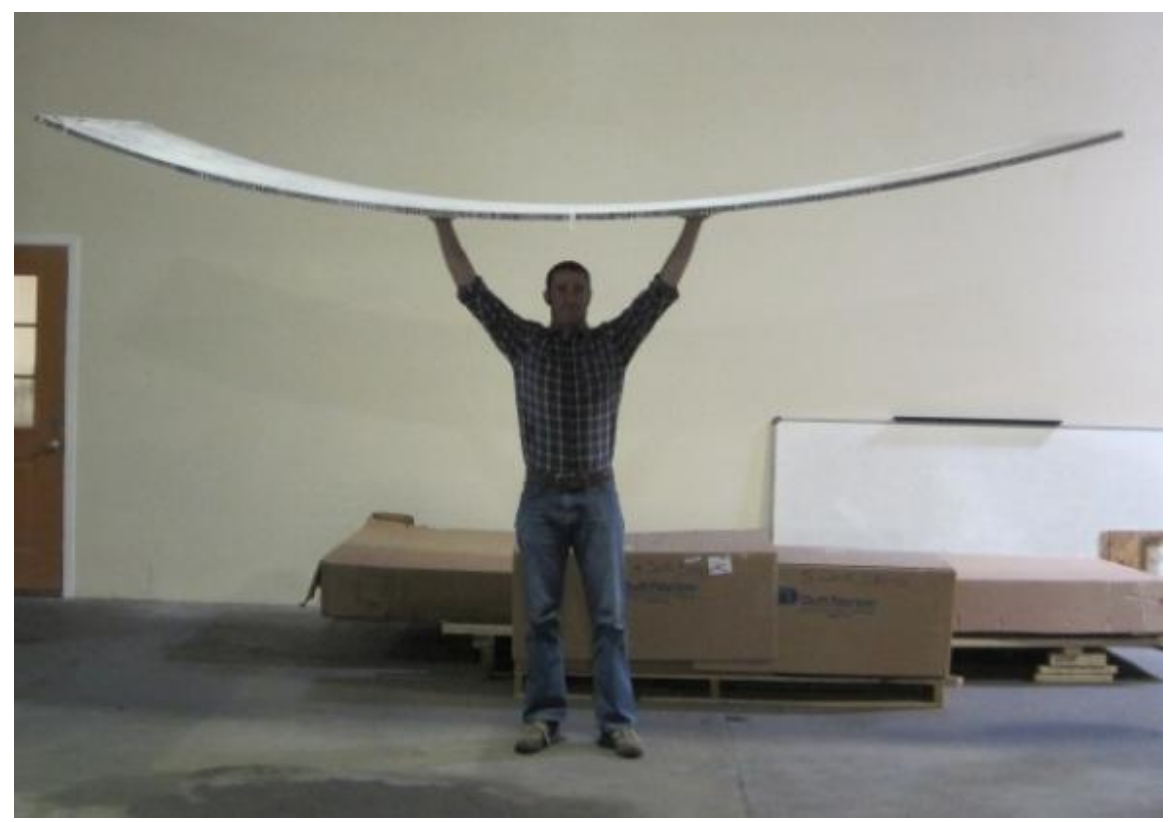

Figure 16. The incredible light weight of the full size prototype panel

\subsection{Task 14: Test Durability Performance}

\subsubsection{Summary}

The objective of Task 14 was to complete a series of durability testing on samples from the best depositions. The analysis will provide us with the insight on the viability of the sample as an outdoor product. The durability tests were conducted at NREL using reflectometer testing, accelerated weather testing and scrub testing on sample ASI 120801

Durability tests showed a variety of results depending on the test. Prior to durability testing, reflectance measurements were conducted to compare reflectance data collected at Abengoa to data collected at NREL. The results show a good match between NREL and Abengoa data. Select samples were durability tested using two different weatherometer tests, a water permeation test and finally scrub testing. The objective of the weatherometer testing was to see how the reflective films would do in hot moist $\left(44^{\circ} \mathrm{C}\right.$ and 90 humidity) and a slightly drier and hotter $\left(60^{\circ} \mathrm{C}\right.$ and $60 \%$ humidity at 2 suns intensity) environment. Visually, neither sample appeared to degrade. Under the microscope however, the number of pinholes appear to increase.

In the water permeation test, the sample was subjected to $100 \%$ humidity under different temperatures $\left(5^{\circ} \mathrm{C}\right.$ and $\left.25^{\circ} \mathrm{C}\right)$. The purpose of the permeation test was to test the barrier properties of the Alumina layer. Data collected during the hours of 
testing show an increased degradation when increasing the temperature from $5^{\circ} \mathrm{C}$ to $25^{\circ} \mathrm{C}$. Images of the sample post permeation test show a large white circle which is the same radius as the water inlet tube diameter in the permeation system. Closer images of the white circle reveal large areas of Alumina loss and fine crystal like structures. In addition to permeation testing, scrub testing was also conducted on the samples. The scrub testing was used to simulate 30 years of cleaning in the field. Very little reflectance degradation was observed on most of the samples post scrub testing. The one sample, from the area over e-beam gun 3, did show some degradation after the scrub testing.

\subsubsection{Task Results}

Only one sample was tested by NREL, ASI 120801, which represented the most promising sample to date. The sample was split into 3 sections, measured as a percent of the film width from the reference edge of the film. The first was over ebeam source 1 (at roughly $25 \%$ ) the second over e-beam source 2 (at roughly $50 \%$ ) and the third was over e-beam source 3 (at roughly $75 \%$ ). To simplify labeling the sections are referred to as 1,2 and 3 for $25 \%, 50 \%$ and $75 \%$, respectively. Wide crazing bands exist over section 1 and section 3 and a very narrow band exists over section 2 . It is important to note that section 3 was without ion assist, thus had a wide craze band.

\section{Reflectance Testing}

To compare reflectance measurements at Abengoa and NREL, reflectometers SOC 410 and D\&S were used on sample ASI 120801. As mentioned previously, the SOC 410 is used for the solar weighted average over a broad range, $335 \mathrm{~nm}$ to $2500 \mathrm{~nm}$. The D\&S reflectometer, on the other hand, measures the specularity of the film at a single wavelength, $660 \mathrm{~nm}$, using three different apertures $7 \mathrm{mrad}, 15$ mrad and 25 mrad. The reflectance measurements of NREL can be found in Figure 17. The reflectance measurements shown are averages of roughly 3 to 5 points per area.

The solar weighted average reflectance measurements show only a minor difference between what was measured at ASI and the measurements performed at NREL. The area with the greatest difference is in section 3 at $91.8 \%$ versus $95.37 \%$, for ASI and NREL respectively. The large difference may have been due

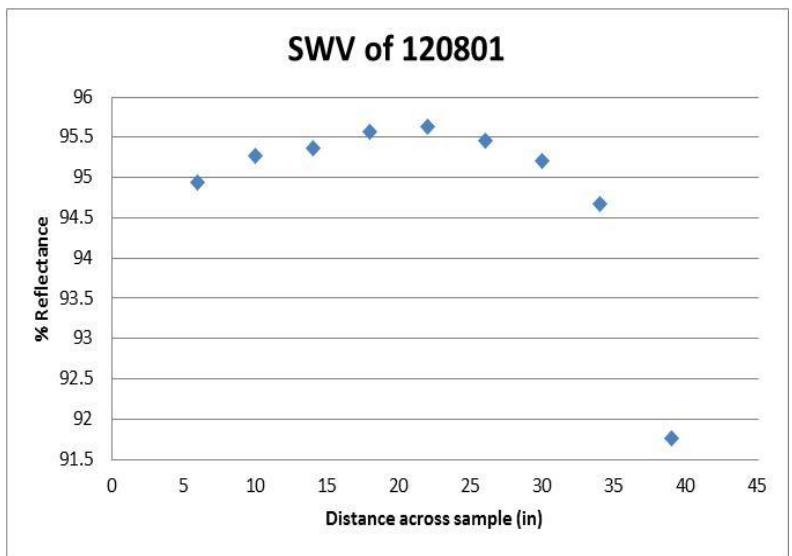

Figure 17. Solar weighted average reflectances of 120801 in the transverse direction. to the area of testing. As observed in Figure 17, a large reflectance roll off is observed towards the edge of the film. 
This is most likely do to the lack of ion assist in this section. Ion source 3 was not functioning during the deposition of this film.

In contrast, the D\&S measurements conducted at 7 mrad show a very large drop in reflectance for each section tested. The greatest difference at $7 \mathrm{mrad}$ was from over section 1, where the reflectance dropped from $82.5 \%$ to $56.57 \%$. The reflectance measurements at either 25 mrad or 15 mrad were fairly consistent between ASI and NREL. The reason for such a large drop is most likely due to crazing and/or warping. Low values can be observed if the measured area is not completely flat or if crazing is deflecting some of the light. At $7 \mathrm{mrad}$, any small deflections could change the reflectance values dramatically.

\section{Accelerated Weathering Testing}

Weathering tests were conducted to evaluate the barrier properties of the sample's coating. Three different systems were used for accelerated weathering testing conducted on sample ASI 120801 section 2 . The three different systems are the Blue M $\left(44^{\circ} \mathrm{C}\right.$ and $90 \%$ humidity), $\mathrm{Cl} 5000\left(60^{\circ} \mathrm{C}\right.$ and $60 \%$ humidity at 2 suns) and Aquatran water permeation system. For the water permeation test, the sample was exposed to water at a given temperature and a sensor on the opposite side of the sample measures the amount of water vapor that permeates through the sample.

Of the three different weathering tests conducted, two gave positive results whereas the third showed an almost total failure. The Blue $\mathrm{M}$ and $\mathrm{Cl} 5000$ tests were run for about 28 days without any apparent degradation in the alumina coating. Results of the two tests are shown below in Figure 18 and Figure 19. The crazing/cracking that are visible in the close-up images existed pre weathering test

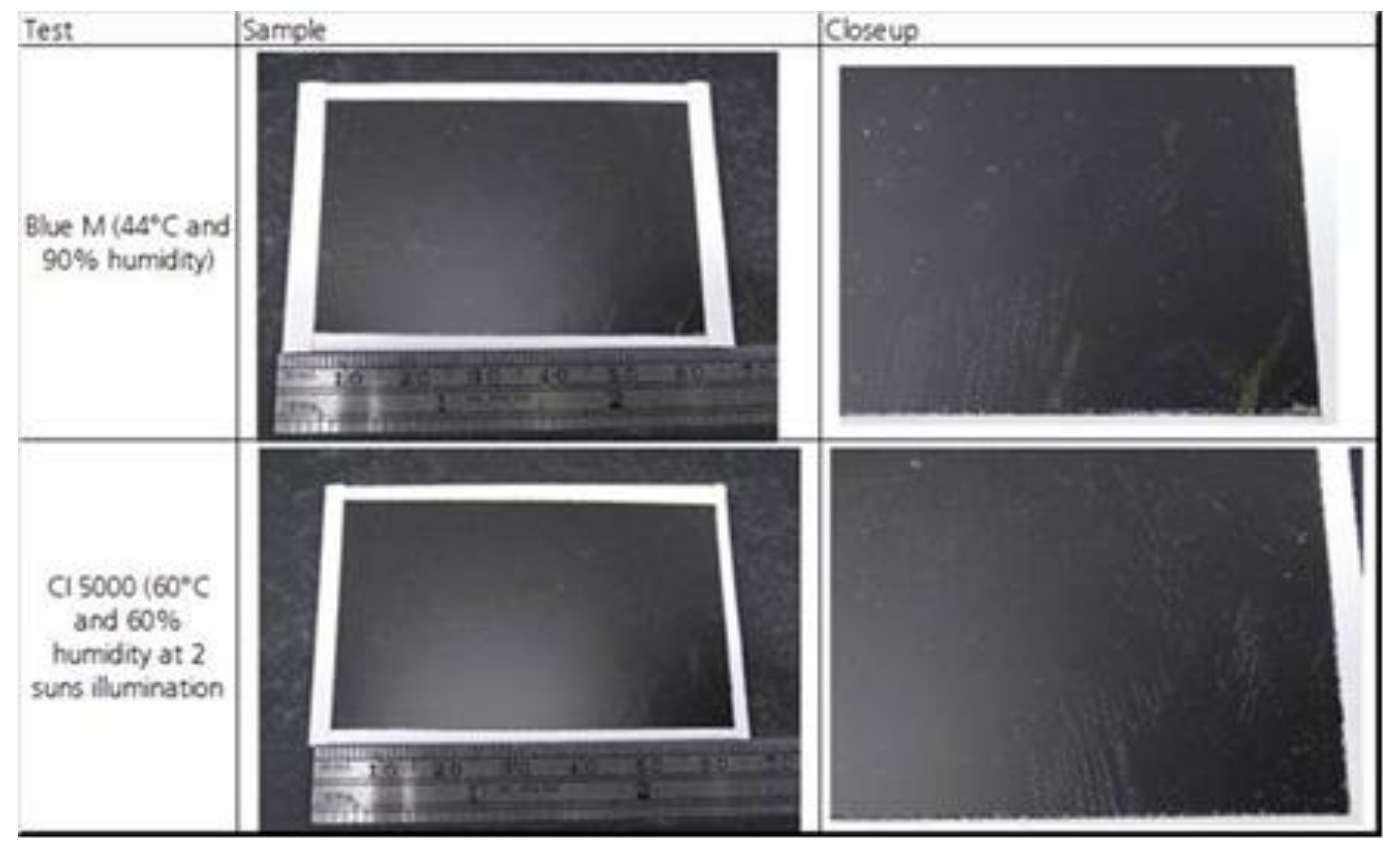

Figure 18. Post weathering, sample ASI 120801. The full samples are shown on the right side while a close up of some of the defects are on the left side 
and are most likely due to handling of the film. There does not appear to be any color change or clouding of the Alumina layer. Images from the microscope reveal some blistering that was not previously observed. Both samples from Blue $\mathrm{M}$ and $\mathrm{Cl}$ 5000 exhibited the blistering, ranging from 80 um to 200 um in diameter.

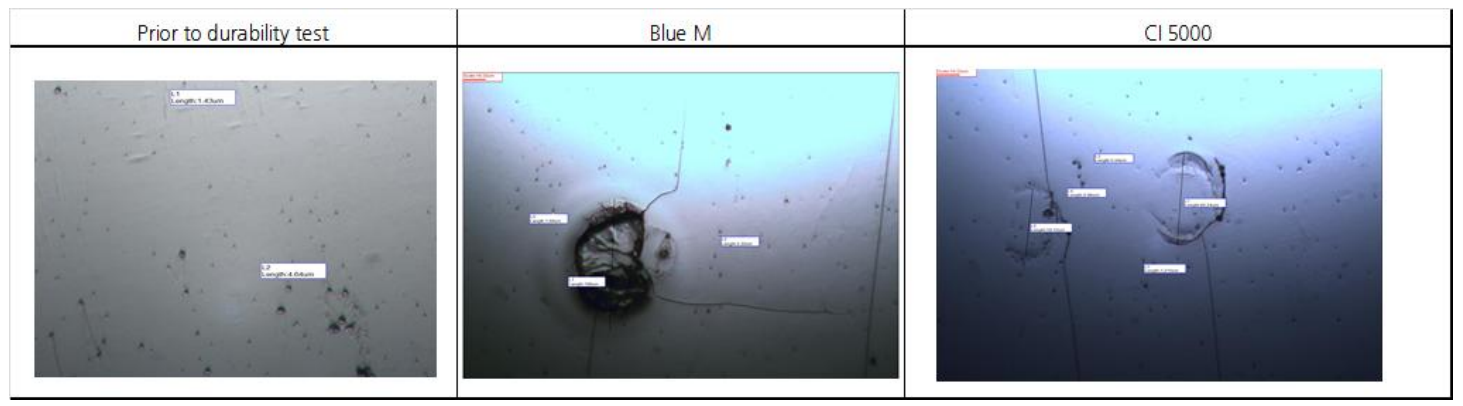

Figure 19. Microscope images of the samples prior to and post weatherometer testing. On the far right is the sample prior to weatherometer testing, in the middle is the sample post Blue $\mathrm{M}$ testing, and on the right side is the sample post $\mathrm{CI} 5000$ testing

The water permeation was also tested on the 120801 sample on section 2. The first sample tested failed very fast and images show various regions of delamination. However due to some sample preparation questions of the film, another test was conducted. Permeation tests from the second tests are shown in Figure 20. The test began at a low temperature, $5^{\circ} \mathrm{C}$. During the roughly 100 hours the water permeation did not appear significant.

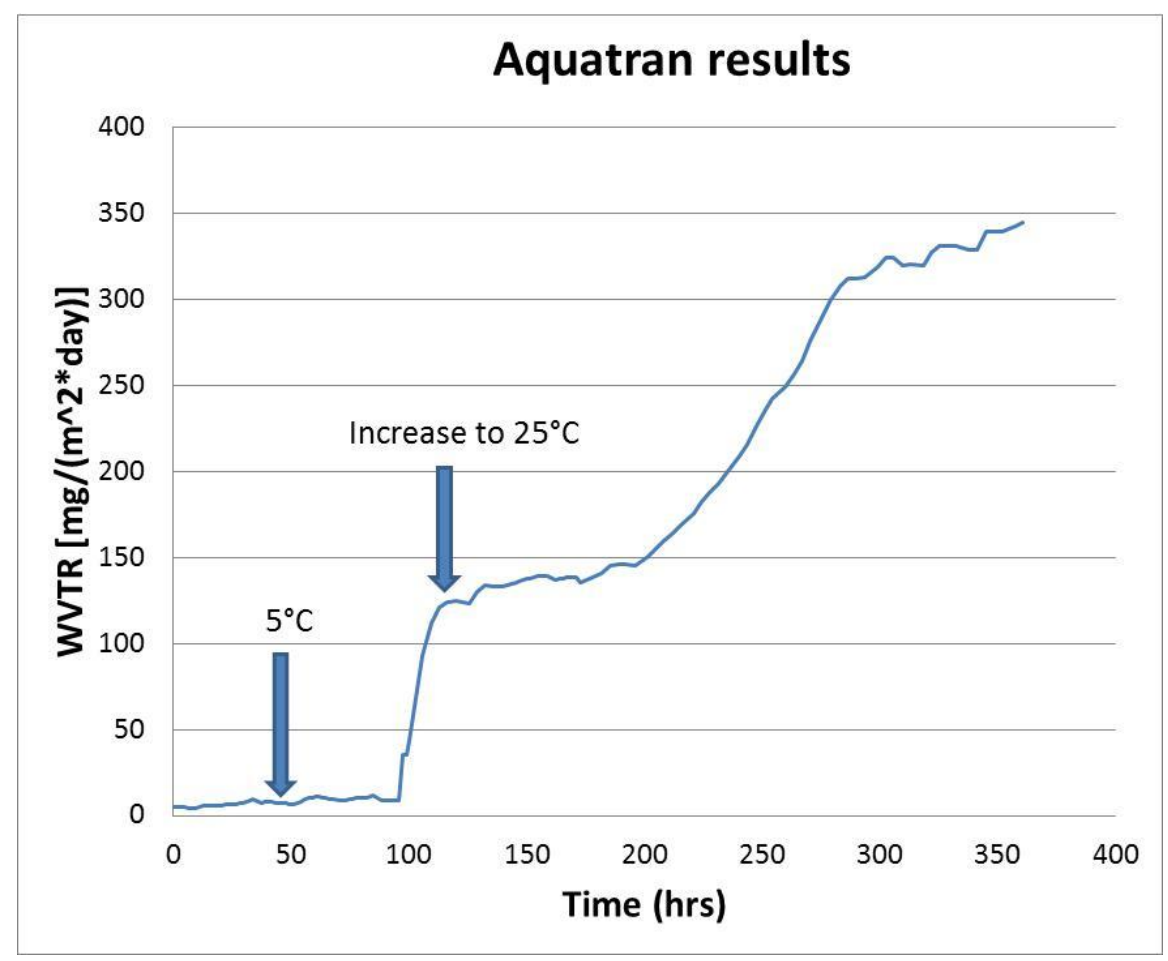

Figure 20. Water permeation from 120801 from section 2 of the web 
The temperature of the water was increased to $25^{\circ} \mathrm{C}$, which dramatically accelerated the permeation through the sample. For the first 100 hours a slow degradation of the film was observed. At roughly 200 hours, the slope increases significantly, signaling a breakdown of in the sample. At about 280 hours the slope again changes to a less dramatic increase but was still increasing overtime. The test was concluded after roughly 350 hours, with 250 hours at $25^{\circ} \mathrm{C}$. Images of samples post testing are shown on the in Figure 21 . Unlike the images from the Blue $\mathrm{M}$ or $\mathrm{Cl}$ 5000 systems, the images from the permeation testing show a total breakdown of in the sample, including areas of delamination. The white area is where the sample is breaking down, which is the same diameter as the water inlet tube of the water permeation system. The dark spots on the white area are regions in which the sample delaminated. Under the microscope, small fiber-like crystallites appear to form below the cracked barrier layer. The crystallites range in sizes from around 10
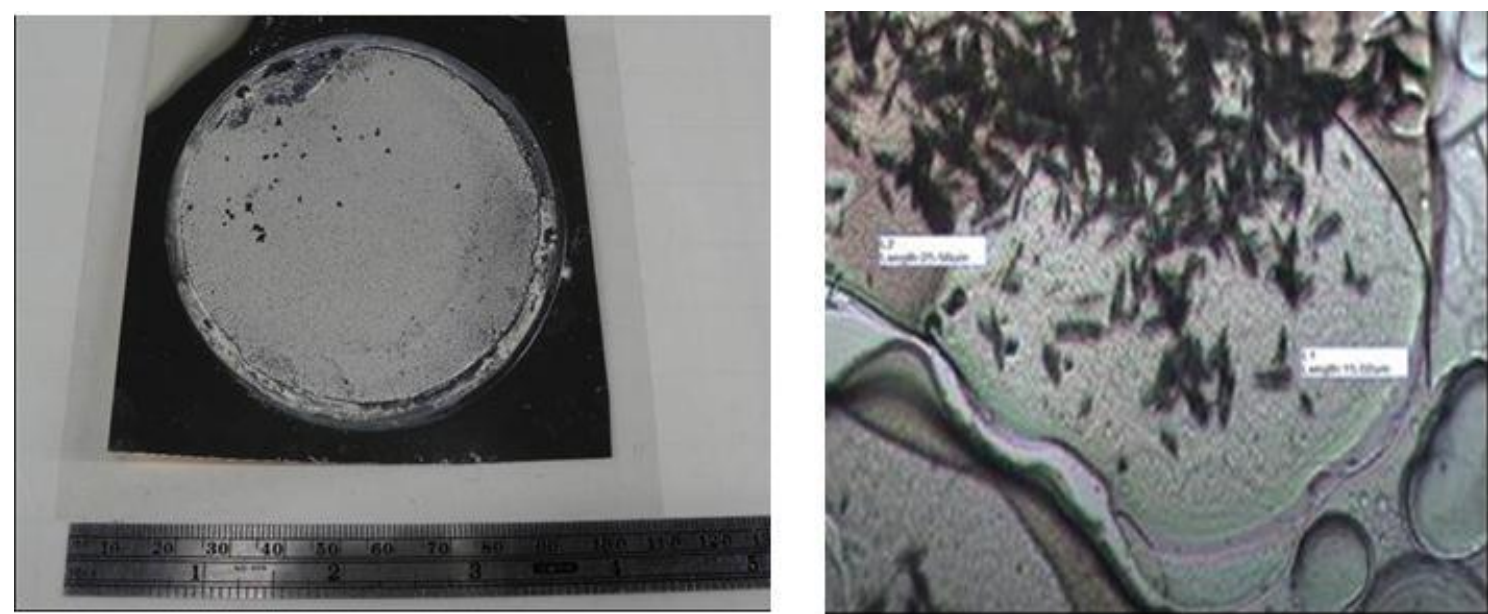

Figure 21. Image of the sample post permeation test. On the left side is the image of the cut sample post permeation test where the white ring represents the area of the permeation test. On the right side is a close up image of one of the areas of delamination

um to around $40 \mathrm{um}$. In addition, water erosion of the barrier layer is apparent by the circular voids. The water used in the permeation testing is Deionized water so salt crystals should not form. At this point it is not clear what the crystals are, additional EDX testing might reveal the composition; however the project has concluded and there is no additional funding to conduct these tests.

The reason for the failure in the permeation test and the success in the Blue $M$ and Cl 5000 tests is still unclear. More experimentation may be needed to examine this further. 


\section{Scrub Abrasion Resistance Testing}

The scrub test system shown in Figure 22 is used to test the durability of the alumina coating over a 30 year period with periodic scrub cleaning. By looking at the reflectance measured via UV-Vis before and after the scrub test degradation in film properties should be visible. A shift in the maxima and minima will indicate degradation in the barrier layer.

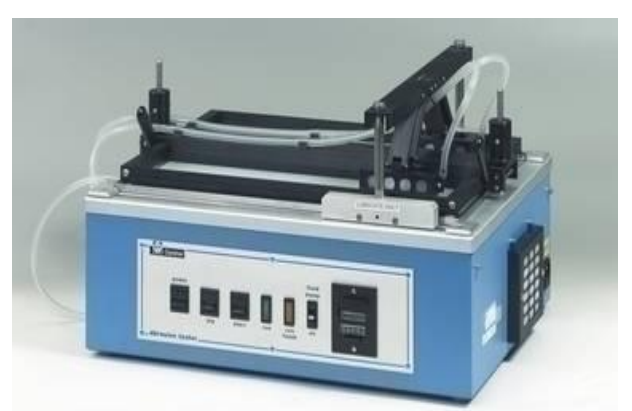

Figure 22. ASTM D2486 Two-Channel Wet Ahrasion Scruh Tester

The results from scrub testing were good and can be seen in Figure 24. Very little loss in reflectance was observed after the scrub test for the section 2 sample. The largest \% loss was in the $1150 \mathrm{~nm}$ to $2500 \mathrm{~nm}$ region, which was around 0.3 to $0.4 \%$. In addition, the maxima and minima still match up so the thickness did not change and there was no degradation of the barrier layer.

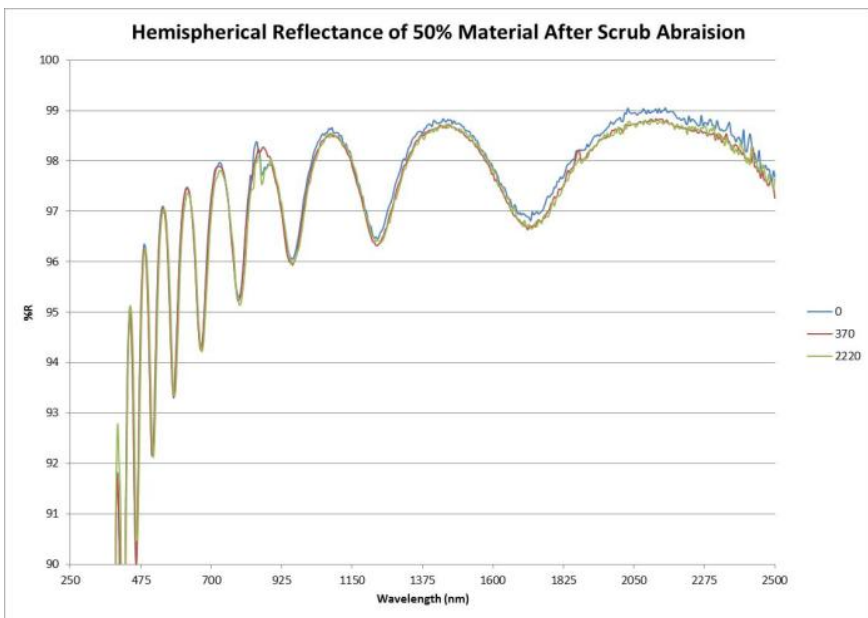

Figure 24 ASI 120801 UV-Vis Reflectance data, section 2 $(50 \%)$ at $0 \mathrm{hrs}, 370 \mathrm{hrs}$ and $2220 \mathrm{hrs}$. of scrub testing

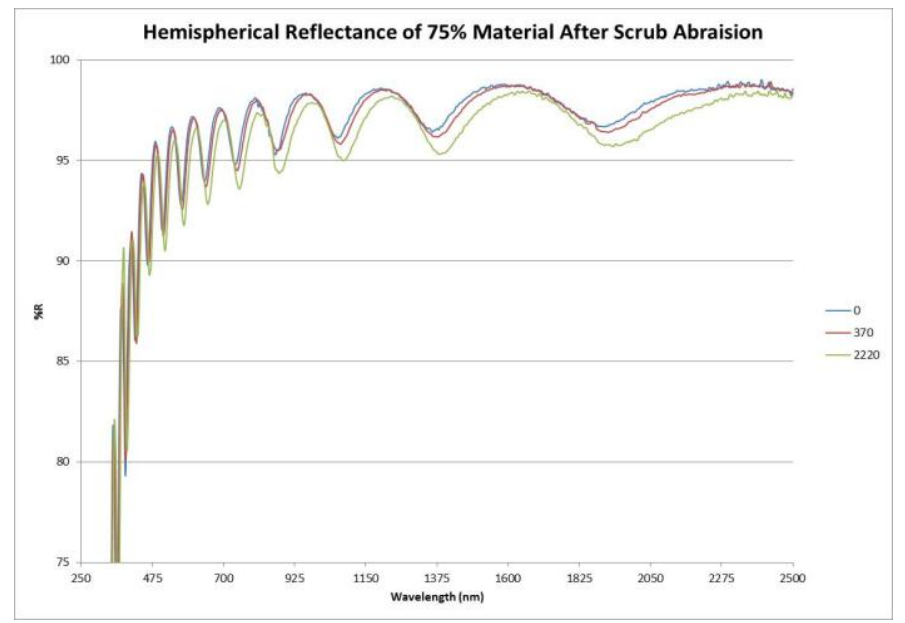

Figure 23 ASI 120801 UV-Vis Reflectance data, section $3(75 \%)$ at $0 \mathrm{hrs}, 370 \mathrm{hrs}$ and $2220 \mathrm{hrs}$. of scrub testing

The sample taken over section 3 did not fare as well, show in Figure 23. A loss of about $1 \%$ was observed over a very broad area $(475 \mathrm{~nm}-2500 \mathrm{~nm})$. In addition, a slight shift was observed in the maxima and minima which might mean a change in film thickness or properties. The shift in peaks relates to about an $8 \mathrm{~nm}$ loss in thickness and a lower overall reflectance. The lower reflectance values could occur from the slight oxidation of the Silver layer as the barrier layer breaks down. 
In addition, the samples were measured via reflectometer, SOC 410 and D\&S, before and after the scrub test, shown in Table 3. For the solar weighted average, a significant change in reflectance was not observed for either section 2 or 3 of the ASI 120801 sample post 2500 cycles. In addition, only about a $0.1 \%$ loss in specularity was observed $25 \mathrm{mrad}$ and $15 \mathrm{mrad}$ in section 2 . A gain of about $2 \%$ at 7 mrad was also observed for section 2 . It is possible the increase in specularity of the film is a function of the curvature of the sample pre and post scrub testing. A flatter surface may produce higher values at the $7 \mathrm{mrad}$ aperture.

Table 3. Reflectometer data before and after scrub testing for sample 120801 sections $2(50 \%)$ and $3(75 \%)$

\begin{tabular}{|c|c|c|c|c|}
\hline & \multicolumn{2}{|c|}{ Before Scrub } & \multicolumn{2}{c|}{ Post Scrub } \\
\hline Section & $\mathbf{2}$ & $\mathbf{3}$ & $\mathbf{2}$ & $\mathbf{3}$ \\
\hline \multicolumn{5}{|c|}{ SOC 410 } \\
\hline \hline SWV (ASTM G173) & 95.56 & 95.37 & 95.58 & 95.39 \\
\hline \hline \multicolumn{5}{|c|}{ D\&S } \\
\hline \hline 25mrad & 93.8 & 94.4 & 93.80 & 94.80 \\
\hline 15mrad & 92.1 & 93.3 & 93.10 & 93.80 \\
\hline 7mrad & 67.7 & 70.3 & 70.10 & 58.50 \\
\hline
\end{tabular}

Similar to section 2, the specularity in section 3 was about the same pre and post scrub testing. Unlike section 2, the specularity at 7 mrad in section 3 did not improve post scrub test. A drop of roughly $12 \%$ was observed at the $7 \mathrm{mrad}$ aperture. The large drop at the $7 \mathrm{mrad}$ aperture may be showing the signs of degradation of the barrier layer, similar to the UV-Vis scan. More tests will be needed to verify this notion. 


\subsubsection{Conclusions}

Durability results showed a good match between NREL and Abengoa data in reflectance data. In addition, weatherometer tests, water permeation tests and scrub tests were conducted on separate samples. Samples before and after weatherometer visually looked identical however under the microscope blisters in various locations were observed. The blisters may have been due to water finding a pathway through the barrier layer. Most of the time the blisters were found at or near cracks in the film, which might suggest that water seeps through the crack. Another possibility is that deep pinholes allow the water to enter under the barrier layer and blister the surface thus causing cracking The amount of blistering did not seem to differ based on the type of weatherometer system tried.

In addition to weatherometer testing, water permeation testing was conducted. Severe degradation of the barrier layer was observed during the water permeation test. Visually, a white circle was observed. Additionally analysis via microscope revealed severe erosion of the barrier surface from the water. Several small crystallites were also observed ranging in size from 10-40 um in size. The crystallites appear to be below the barrier surface. The composition of the crystals is still unknown.

In addition to permeation testing, scrub testing was also conducted on the samples, to simulate 30 years of cleaning in the field. Reflectance data and UV-VIS measurements show very little reflectance degradation post scrub testing. Section 3 had the largest drop in reflectance post scrub testing, with a drop of about $12 \%$ at 7 mrad. The scrub testing shows that despite pinholes and cracking, the samples can still survive a 30 year scrub test without much degradation.

\subsection{Task 15: Test on Panel/Collector}

\subsubsection{Summary}

ASRM samples produced in Task 10 will be adhesively laminated to a structural support and integrated into a component of a subsystem for full scale testing of technical requirements. Cost data can also be gathered during this process to demonstrate system level fabrication costs.

Delays in producing a reflective film that was consistently adherent precluded onpanel testing. Without a film prototype available, lamination and deployment activities could not start during the course of the project timeline. As such, there was no significant progress on this task.

\subsubsection{Results}

The team put together an initial plan for lamination and deployment; however, we delayed any significant effort based on the need for deployable film. 


\subsection{Task 16: Update Cost Model}

\subsubsection{Summary}

The objective of Task 16 was to update the ASRM cost model for process modifications developed under Combined Phase 2 and 3. The cost model was modified to reflect the process parameters near the end of deposition trials. The model was then used to explore possible future production scenarios and impacts of changes from the combined Phase 2 and 3 . Task 16 results are based on a model of the deposition process and show projected film costs on a per square meter basis, which is then used as an input to the solar plant/system cost models in Task 17.

The cost model uses over 35 inputs from process variables to material and factory utilization and costs. While there are many contributing factors, analysis shows the primary cost model driver is the total ASRM area produced per year by a production machine. This stems from the large capital requirements for a production deposition machine. The machine cost is amortized into an annual cost that is divided by the annual ASRM area produced (i.e., annual capacity) to determine a per square meter cost. After reviewing a set of scenarios and process conditions, the annual capacity is primarily dependent on effective deposition rate and target barrier thickness. These produce film costs, using the Phase 1 production system cost estimate, within the original cost goals of the project. However, once the model incorporates the production system quote obtained at the end of the combined Phase 2 and 3, film costs rise well above film cost targets.

\subsubsection{Results}

The cost model used takes over 35 inputs and calculates an estimated annual cost per square meter of ASRM produced. The baseline case cost model takes inputs from the last runs conducted by the project (Fall 2012), using the best recorded deposition rate. The annual cost per square meter represents the final output of a step by step modeling of the project's Ion Beam Assisted Deposition (IBAD) process.

\section{Production Stages}

The cost model uses a cycle of stages to represent the deposition process: equipment turnaround and pump down, deposition, up to atmosphere time, and unloading time (Figure 25). Each stage accumulates time and accounts for materials and labor costs. The deposition stage uses the maximum diameter of the 'completed product' roller as the limiting factor based on typical capacity of produc-

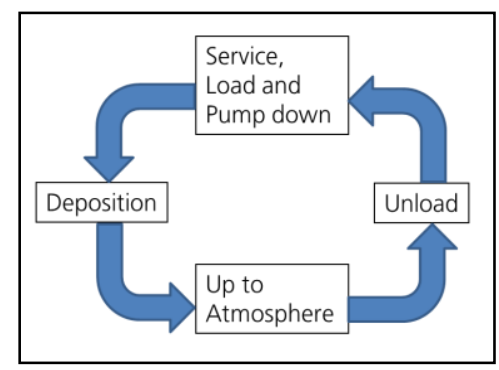

Figure 25 Model Production Stages tion vacuum chambers. Each time a deposition cycle is complete, time is lost going through the production stages, lowering the annual production of the deposition chamber. Once a deposition stage is complete, additional time is needed to come 
up to atmosphere, clean and maintain equipment, pump back down, and get sources warmed up to steady state for the next deposition stage of a new cycle.

The accumulated times for all the stages of a cycle give the production hours needed to produce one roll of ASRM. By combining the production hours to produce one roll with the annual operational hours (i.e., operational capacity), the total rolls per year can be calculated, allowing for total annual ASRM capacity to be calculated. The input deposition rate determines how much material can be deposited per unit time and is thus a primary factor in annual capacity. The sensitivity of final cost to rate rises as the production system cost rises.

Operational Capacity

The cost model includes an uptime factor in the operational capacity, to account for power outages, forced maintenance, and other unexpected issues. The uptime factor reduces the available operational time thus reducing the estimated total ASRM square meters year. On the other hand, depositing metals produces significant build-up around the target which can be reclaimed, providing a credit back that reduces the cost per square meter.

\section{Physical Characteristics}

The cost model uses physical dimensions of the film to find material costs based on input source costs. The film width, roll length and layer thicknesses are combined with metal, oxide, and substrate costs to give an estimate of total material costs per roll. Combining the total material costs per roll with the total rolls per year, the total material cost per year can be calculated. Material costs generally scale with annual capacity, as the more film a system produces; the more physical material is consumed.

The relative contribution of material costs to baseline film costs was surprisingly low, even with use of valuable metal layers (silver and copper). The low relative contribution is in part from using thin layers (e.g., 100nm of Silver and $50 \mathrm{~nm}$ of Copper) whose excess deposition can be reclaimed. The model assumes $30 \%$ metal yield on to the film and an $80 \%$ reclamation rate applied to the remaining $70 \%$ that is deposited onto internal shielding. The relative cost breakdown for the Phase 1 baseline is shown in Figure 27, with just $10 \%$ at-

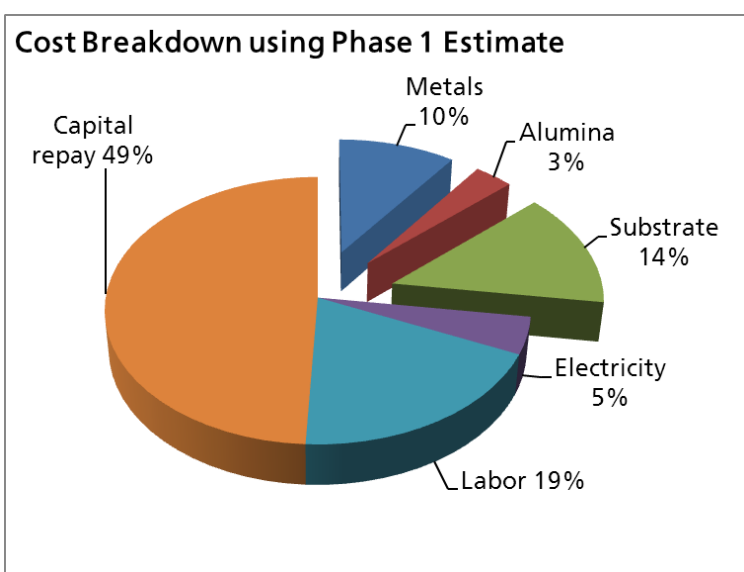

Figure 26 Modeled Film Costs for Phase 1 baseline tributed to the metals consumed.

The dominant cost impact of the film's physical characteristics is barrier thickness. The thickness of the layer is directly proportional to the length of time to produce ASRM film, i.e. the thicker the barrier layer, the longer the film will take to produce. 
Unfortunately, the layer thickness can have a large impact on barrier properties, with a thicker protective layer generally providing more benefit. The team found a relatively cheap source alumina, so the relative contribution of the material is only about $3 \%$. However, the largest increase in film cost is not due to material used but by the increased production time and reduced annual ASRM production capacity of creating a thicker film versus creating a thinner film. With fewer annual square meters produced, factors that do not depend on annual capacity (e.g., Capital repayment) become more dominant in the overall film cost calculation.

\section{Facility and Chamber Costs}

The cost model includes facility and loan repayment as a part of production costs. The inclusion of the load repayment is based on the assumption that the commercialization of the technology leads to the financed purchase of special purpose production vacuum chambers. The loan encompassed the engineering costs associated with the first machine, as with any new design, and it is assumed that subsequent machines will be less expensive as the engineering costs are greatly reduced. In the cost model, the impact of the initial engineering costs will be reduced due to the assumption of using several deposition systems in the future, these without the initial engineering burden.

In Phase 1, the cost of a production vacuum system was estimated by Swisher based on verbal discussions with a possible vendor. At the end of the combined phase a formal quote was obtained including specifications based on the work from Phase 2 and 3. The formal quote was roughly twice the amount estimated cost in phase 1. The increase in equipment cost represents a significant challenge, as capital repayment was half of our film cost at the Phase 1 estimated cost level

In addition, material usage is now only $17 \%$ and reducing material usage will have a relatively low impact. In order to drive down the cost impact of Capital repayment, since it is a fixed cost per year, annual capacity must be increased. That would divide the Capital repayment burden over a larger number of square meters produced, resulting in a smaller per square meter film cost.

\subsubsection{Conclusions}

Using best input values from work over the combined Phase 2 and 3, with the Phase 1 production system cost estimate, the cost model estimated a film price below the project cost target. However, once the Phase 2 and 3 production system quote was used to update the model, the estimated film cost rose well above cost targets.

Based on the cost breakdown for the updated model, the annual capacity must be the focus of additional work; this requires reducing the time required to produce a unit area. The direct approaches to reducing production costs follow:

- Reduce the barrier layer thickness,

- Use a wider substrate and deposition system, 
- Increase the alumina deposition rate.

Earlier work on using a thinner barrier layer show less than ideal results and vendor feedback suggests that wider than our specification $(2 \mathrm{~m})$ becomes difficult for our approach. Over the course of Phase 2 and 3, the project has attempted to maximize deposition rate and found that PET, in our high rate cases, was at or beyond its stable thermal limit. In addition, the ASRM micro structure was degraded as the deposition rates were pushed high and, the team believes, to their limits in the prototyping system.

\subsection{Task 17: LCOE Analysis}

\subsubsection{Summary}

The objective of Task 17 was to perform an LCOE analysis to show the contribution of the film to lowering energy costs. This analysis requires combining film cost modeling results from Task 16 with collector designs and costs, based on the use of film on the composite panel from Task 13.

The best case film costs are within the original cost goals of the project; however, over the course of the project, glass parabolic mirror costs have dropped dramatically. The reduction in glass mirror prices has squeezed the cost benefit of alternate reflector solutions. While there is still a reportable advantage to the initial composite panel with reflective film ( $4.41 \%$ LCOE reduction), the overall system advantage is lower than it would have been when the project was proposed.

\subsubsection{Task Results}

\section{System model}

Abengoa Solar uses an in-house system model to determine the aggregate performance and cost of a selected nominal plant design. The nominal plant used by Abengoa Solar R\&D is an R\&D target plant and developments are assessed for their relevance and benefit to that future plant design.

For a given plant design and components, performance and costs are treated separately, and then brought together in the final financial analysis by NREL's System Advisor Model (SAM) to generate a Levelized Cost of Energy (LCOE). Plant performance is calculated through a set of interacting sub-system models: solar field, storage system, heat transfer fluid (HTF) process components, and power block. The plant costs are calculated by accumulating sub-system costs for the nominal design.

For this analysis, the team compared large aperture collectors, one design using mirrors and the other using a composite panel with Reflective Film. Solar input to the system was from a Gila Bend, Arizona Typical Meteorological Year (TMY) currently used by Abengoa Solar for modeling its Solana plant. 


\section{LCOE based on system model}

The LCOE calculations are based on a wide range of inputs (more than 50), each of these being best guesses, or aggregations themselves of other factors LCOE differences between a specific case and a baseline case are used to guide choices of research direction and show the relative benefit of the specific technology case versus the baseline case. The calculated potential difference between using Reflective Film composite panels and traditional mirrors is $4.4 \%$. The team's estimate of uncertainty in the LCOE delta between cases is $10 \%$, giving $4.4 \% \pm 0.4 \%$ cost difference.

The module design using the Reflective Film Composite Panel accounts for about $29 \%$ of the LCOE savings, primarily from leveraging its stiffness and strength. The additional accuracy of the module/panel design reduces optical error and allows the use of a smaller and less expensive Receiver Tube. This benefit is slightly reduced by the larger pump needed to overcome additional pressure drop in the HTF system. Assembly of collectors using the reflective film composite panel is much simpler and this generates an assembly labor savings as well as a lower cost fixtures and jigs in the assembly Factory. Higher reflectivity and improved shape accuracy of the film panels generates nearly half of the system cost savings.

\subsubsection{Conclusions}

The final Reflective Film composite panel LCOE savings, based on Module, Receiver, Assembly, Factory, and Energy Production improvements, is $4.4 \%$. This is based on an R\&D target plant using Molten Salt with 6 hours of direct storage, in Gila Bend, Arizona. The estimated cost savings breakdown shows energy production increases are $44 \%$ of the overall benefit and solar field component cost reductions are $56 \%$.

\section{Conclusions}

\subsection{Summary of Results}

Moving from a 12-inch wide to a 30-inch wide deposition area the team was able to obtain high quality coatings. The sample 120801 has both high reflectance (>95\%) and great adhesion.

In addition, the sample was put through durability tests which included scrub testing, water permeation testing and accelerated weathering tests. The results from the scrub testing and accelerated weathering tests were positive. The accelerated weathering tests were conducted using two different systems as described in section 13. A breakdown of the barrier layer was not observed in either test. The water permeation test however was not as positive. A significant breakdown in the barrier layer was observed after about $25^{\circ} \mathrm{C}$ at $100 \%$ humidity. 
In addition, the team looked into composite facet panel materials, down-selecting from the more than twenty materials. The three most promising panels were manufactured for testing purposes. The panels were subjected to accelerated weathering and hail testing at NREL, as well as optical, structural and outdoor testing at ASI facilities. The best panel showed good promise for commercial viability.

Cost modeling and LCOE were also investigated as part of the combined phase 2 and 3 of the project. From cost modeling the film production process, the largest cost contribution comes from the high capital requirement for a production vacuum chamber. This means that cost reduction measures must focus on getting more film from a machine: reduce the barrier layer thickness, make a wider film, or increase the alumina deposition rate. At the highest rates seen in the combined phase 2 and 3 depositions, the LCOE savings estimate for using the ASRM on a composite panel is $4.4 \%$. This is based on cost and performance improvements in Abengoa Solar's system model at an R\&D reference plant using Molten Salt with 6 hours of direct storage, in Gila Bend, Arizona. The estimated cost savings breakdown shows energy production increases account for $44 \%$ of the overall benefit and solar field component cost reductions account for the remaining $56 \%$ of benefit.

\subsection{Challenges Encountered}

Throughout the project's combined phase 2 and 3, several challenges were encountered, from equipment issues to dealing with the limitations of the materials involved with the thin film deposition. Months were lost due to issues with equipment failures and leaks developed in the system.

Another large challenge encountered was the limitations of the PET substrate. Overheating the PET web was a constant challenge. The cause for the majority of overheating on the PET web was from the ion beam systems. The challenge was finding a cross over point between crazing and warping. When the ion source was high enough to prevent crazing, the PET was prone to warping or burning through. Without the ion source assistance, severe crazing was present in the mirror film.

To help reduce crazing either the ion source assist needs to be increased or the deposition rate needs to be decreased. By running a decreased deposition rate, the cost per square meter goes up dramatically. During the deposition process, the ejection of source pieces were prevalent at deposition rates greater the $5 \mathrm{~nm} / \mathrm{s}$. The ejected material can damage the film and jams the e-beam crucible drive.

Ion source coverage was also another challenge encountered. While the three grid system allows for longer runs, the beam is also more collimated than the two grid setup. To account for the collimated beam, the ion sources had to be tilted which limited the total ion assisted area to under 1 meter wide. In the future, a linear ion source may be needed to assist wide deposition zones. 


\subsection{Lessons Learned}

Throughout this project several lessons were learned, which will help with further projects. While PET is a great substrate for low temperature processes, due to its low cost and highly level surface, at high temperatures several issues arise: severe warping and melting through the web. In addition, a higher temperature the mismatch in coefficient of thermal expansion between PET and the barrier becomes more evident in the form of crazing. The limitations in temperature, limits the deposition rate possible which has a direct effect on the financial viability.

Ion source coverage was another lesson learned. Initially, small end-Hall systems were used to try to give the best coverage and a low cost. After a few issues in dealing with the end-Hall systems, the gridded ion source was used. The gridded ion source was used in earlier experiments with the reflective film with great results. However, the ion beam coverage from the gridded ion source was not enough to cover the full area of the web. The ion sources had to be tilted to obtain an area of full ion beam coverage. For future work linear ion sources or some other ion assist may work best.

The next lesson learned was the deposition process. Depositing using an e-beam system proved to be problematic, especially at high deposition rates $(>8 \mathrm{~nm} / \mathrm{s})$ where severe spitting was endemic. Several approaches were taken to minimize the spitting, such as changing the sweep patterns, changing the source material and slowing source trough rotation speeds. Unfortunately spitting persisted at high deposition rates.

The last significant lesson learned in this process was that vacuum systems are operationally delicate, as events such as leaks (e.g., chamber penetrations, gas lines, cooling lines, electrical lines, etc), oxide and conductor build-up in the chamber and arcs in the deposition equipment accounted for significant downtime. Any system perturbation (i.e. adding or removing any components or connections) became a real risk item.

\subsection{Conclusion}

In conclusion, the team was able to largely meet the initial project goals when depositing on a limited width and at a modest rate. However, expanding to wide deposition at aggressive deposition rates did not produce consistent film quality. Economic viability drives the process to maximize deposition rate, but the current system configuration has a limiting upper rate threshold that does not appear viable. For future work, other approaches seem needed to address the challenges encountered in the latter scale-up phase of this project. 